\title{
Is the Art Market More Bourgeois Than Bohemian?
}

\author{
Jenny Schuetz* \\ Richard K. Green \\ Sol Price School of Public Policy \\ University of Southern California \\ (Accepted for publication in Journal of Regional Science)
}

March 1, 2013

\begin{abstract}
Media and academic attention to the art market has mostly focused on the high end, composed of famous auction houses and a few well-known international dealers. In this paper, we use a newly developed database to examine the industry structure and location patterns of the broader New York art market, which consists largely of small, independent and relatively unknown galleries. We find that Manhattan galleries are highly spatially concentrated, and that clustering reflects both agglomeration economies and preferences over location-specific amenities. As predicted by theories of agglomeration economies, new galleries are more likely to open in neighborhoods with existing gallery clusters, and proximity to other galleries increases firm and establishment lifespan. We also find evidence that new galleries locate in neighborhoods with high population density and more affluent households, consistent with location models of luxury retail. The results are not consistent with the hypothesis that galleries locate in cheap, "bohemian" neighborhoods, as proxied by several demographic and economic variables.
\end{abstract}

Keywords: Agglomeration economies; retail location; cultural industries; art galleries JEL codes: L81, R12, R33

Acknowledgements

USC's Lusk Center for Real Estate has provided generous financial support for this project. We are grateful to Elizabeth Currid-Halkett for her assistance in developing the dataset and researching New York's art history. We thank Bob Van Order and Chris Redfearn for their insightful comments. Ray Calnan, Vivian Ho, David Pirko and Haoran Zhu provided excellent research assistance. Staff at the New York and Los Angeles Public Libraries graciously assisted with primary research materials, and Hi-Tech Outsourcing Services provided data entry services.

*Corresponding author: 650 Childs Way, RGL 224, Los Angeles CA. jschuetz@price.usc.edu 


\section{Section 1) Introduction}

Academic research and media attention on the art market has mostly focused on the high end of the market, composed of famous auction houses (Sotheby's and Christie's) and a few well-known international dealers. Relatively little is known about the lesser-known galleries that make up the broader art market. Case studies of individual neighborhoods, such as New York's Soho and Chelsea, suggest that galleries tend to form high density clusters. In this paper, we use a newly developed database to examine the degree of spatial concentration among Manhattan art galleries and to explore why the retail art market might exhibit clustering. In particular, we test whether spatial concentration among galleries reflects agglomeration economies or facilitates access to shared resources or amenities.

The primary economic function of galleries is to sell original works of art. By definition, original art is a highly differentiated product: each piece is distinguished by unique aesthetic characteristics and authorship. Compared to many consumer goods, art is an expensive product and a luxury rather than a necessity. Prior research has demonstrated that clustering may benefit retailers that sell quality differentiated and expensive products (Dudey 1990; Eaton and Lipsey 1979; Fischer and Harrington 1996; Picone et al 2009; Stahl 1982; Wolinsky 1983). ${ }^{1}$ Because consumers' choices are driven by idiosyncratic aesthetic preferences, they are likely to engage in extensive comparison shopping to find the "right" artwork, so galleries will compete based on specific product characteristics (for instance, sculpture versus prints or Impressionist versus Pop Art) rather than price (Thompson 2008). Geographic co-location of galleries that specialize in particular types of art work will reduce consumer search costs and may increase volume of visitors for galleries in a cluster. Other retail submarkets that benefit from agglomeration

\footnotetext{
${ }^{1}$ An extensive literature documents clustering benefits on the production side, such as shared learning in research activities, but these are less relevant for retail firms.
} 
economies and often form specialized shopping districts include antiques, jewelry, and shoe stores (Fischer and Harrington 1996).

Even if galleries do not explicitly choose to locate near one another, they may cluster to share access to locally-specific amenities. Classic retail models highlight access to a shared consumer base for particular products (Berry 1967; Chung and Kalnins 2001; Huff 1964; Konishi 2005; Fujita and Thisse 2002; Waldfogel 2008). Because art is a luxury good, potential art collectors are likely to be relatively affluent. Moreover, locating near a sophisticated customer base or in a socially prestigious area may increase a gallery's perceived status (Wu 2003). An alternative hypothesis is that social ties between gallery owners and artists will lead galleries to locate near artists' residences, studios, or entertainment venues as part of the overall bohemian milieu associated with the "creative class" (Currid 2007; Currid and Williams 2010; Florida 2002a, 2002b; Kim 2007; Zukin 1989). Because bohemian occupations earn relatively low wages (especially compared with Manhattan's dominant industries, such financial services and law), the bohemian hypothesis suggests that galleries should locate in lower-income, lowerrent neighborhoods that are accessible to up-and-coming creative workers (Comunian 2011; Comunian et al 2010; National Endowment for the Arts 2011; Zukin 1989). Some physical resources may also attract galleries to common locations. Gallery owners may have preferences over neighborhood-specific building characteristics or architectural styles (Shkuda 2010, Zukin 1989). Proximity to employment centers increases the volume of retail consumers generally (Berry 1967), while locating near museums may provide access to culturally-inclined patrons (Comunian 2011; Griffiths 1995; Julier 2005; Mommaas 2004; O’Connor 2002).

This study offers the first large-scale quantitative analysis of art gallery location decisions. We use the newly developed Manhattan Gallery Database, a longitudinal dataset of 
all Manhattan galleries from 1970-2003, to examine the structure and spatial patterns of the largest U.S. art market. ${ }^{2}$ The industry is composed mostly of small, independent and relatively unknown galleries. Galleries are highly spatially concentrated, and gallery clusters are quite robust over long periods of time, despite a high rate of turnover among individual galleries. We estimate location models of newly opening galleries as a function of baseline neighborhood characteristics to test two hypotheses that could lead to concentration: clustering due to agglomeration economies and co-location to access shared resources. Results are strongly consistent with theories of agglomeration economies: new galleries are more likely to open in neighborhoods with existing gallery clusters, and proximity to other galleries increases firm and establishment lifespan. New galleries tend to locate in neighborhoods with high population density and more affluent households, consistent with location models of luxury retail. The results are not consistent with the hypothesis that galleries locate in cheap, "bohemian" neighborhoods, as proxied by several demographic and economic variables. Environmental amenities such as proximity to museums play little role in gallery location choice.

Our current analysis is specific to Manhattan, but the findings may be relevant to other cities that have substantial cultural industries. Cities such as Los Angeles, Chicago, London and Beijing also participate in the global art market. Several smaller cities, such as Santa Fe, NM, Flagstaff, AZ, and Naples, FL, have a large number of galleries relative to population, so understanding the dynamics of cultural industries should be relevant to the economic development of these metropolitan areas. By examining the entire retail art market, not merely the auction houses and most famous galleries, we seek to understand the location patterns of small, independent firms that are likely more typical of those found throughout U.S. cities.

\footnotetext{
${ }^{2}$ According to the Census Bureau's County Business Patterns data, the New York PMSA has the largest number of galleries of any U.S. metropolitan area, more than twice the number in Los Angeles and Chicago.
} 


\section{Section 2) New York City neighborhood art history (1945-2005)}

New York City has long been a national and global center of cultural industries, home to notable artists and arts-related institutions. Over the past half-century, several neighborhoods have been particularly well-known for artists' residences, studios, and social institutions, as well as for notable museums, galleries and auction houses. The arts-related history of these neighborhoods provides some geographic context for the empirical findings in Section $5 .^{3}$ Upper East Side and Midtown

The original centers of New York's gallery activity, the Upper East Side and Midtown, particularly along $57^{\text {th }}$ Street, dominated the city's art market through the mid-twentieth century, specializing in Old Masters and ancient art (Simpson 1981; Kostelanetz 2003). The Upper East Side was the first neighborhood recommended by New York City guidebooks for tourists wishing to browse art galleries. Many of the City's major museums are located in the Upper East Side, including the Guggenheim, the Whitney, and the Metropolitan Museum of Art, or in Midtown, such as the Museum of Modern Art. Both major auction houses, Sotheby’s and Christie's, are also located on the Upper East Side and Midtown, respectively. Midtown is primarily a commercial area and the center of the financial services industry. The Upper East Side has for many years been one of New York's most affluent and prestigious residential enclaves. Historically, major art dealers like Leo Castelli began their careers with Uptown galleries and later expanded to Downtown outposts. While viewed by the media and art critics as less important today than Chelsea, Madison Avenue and 57th Street remain home to major art dealers who sell blue chip artists such Warhol, Matisse and Ellsworth Kelly (Russell 1988).

Greenwich Village: post-WWII-early 1960s

\footnotetext{
${ }^{3}$ Geographic definitions of neighborhoods are discussed in Section 4 and listed in Appendix Table A.
} 
Beginning shortly after World War II, Greenwich Village became widely known as a home for the Abstract Expressionists, and thus became an important location for art production and accompanying art shows. During this time, galleries were concentrated on East $10^{\text {th }}$ Street and artists' residences were located on adjacent streets (Kostelanetz 2003; Perl 2007). In 1951, Leo Castelli, arguably one of the most influential $20^{\text {th }}$ century art dealers, organized the Ninth Street Show, featuring artists such as Jackson Pollack and Willem de Kooning (Herskovic 2000). Abstract Expressionism remained an important art movement through the early 1960s and Greenwich Village continued to operate as the nexus for galleries, exhibitions, artists' residences and their accompanying social institutions (Perl 2007; Currid 2007). However, by the 1960s Soho had begun to emerge as the new center of avant-garde artists.

Soho: 1960-1989

With the decline of Greenwich Village, artists began moving into nearby Soho ("South of Houston"), an area previously occupied by manufacturing and containing a large stock of thenvacant cast-iron industrial buildings (Kostelanetz 2003; Zukin 1989; Simpson 1981). In 1971, the city permitted the rezoning of light manufacturing buildings for artists' work-living quarters and artists-in-residence. This dual use enabled artists to obtain ample space for relatively cheap rents (Zukin 1989; Currid 2007). Zukin (1989) estimates that approximately 600 artists lived illegally in Soho at this time. Often artists retrofitted the upper floors of buildings for studios, with commercial galleries occupying the ground floors. In the early 1970s, some well-known art dealers who ran galleries in Midtown or the Upper East Side opened new galleries in Soho (Kostelanetz 2003; Simpson 1981; Zukin 1989). Soho retained a reputation as a vibrant bohemian-bourgeois district for most of the 1970s and 1980s, but by the early 1990s, major art 
dealers had started to establish galleries in Chelsea, north of Greenwich Village. The decline of Soho's status is frequently attributed to increasing rents (Kostelanetz 2003; Zukin 1989).

East Village: mid-1970s-1980s

Concurrent with Soho's rise, the East Village emerged in the mid-1970s as an important location for the Neo-expressionist movement, including neo-pop, graffiti and other types of avant-garde art, featuring artists such as Keith Haring, Jean-Michel Basquiat, Julian Schnabel, and Andy Warhol (Chalfant and Silver 1983; Currid 2007; Stevens 2005; Taylor 2006). While Soho and Midtown were better known for commercial art galleries, the East Village was viewed as a small, tight-knit bohemian enclave, with artists' residences and nightlife institutions, like the famous club CBGB (Gumpert 2006; Taylor 2006). Small tenements dominate the building stock in the East Village, which may have made the neighborhood less attractive to galleries.

\section{Chelsea: 1990-present}

Several scholars have linked Soho's decline as an art district to the simultaneous growth in Chelsea galleries (Kostelanetz 2003; Molotch and Treskon 2008). A few notable dealers who moved to Chelsea in the mid-1990s set the trend: Mary Boone, Larry Gagosian, and Paula Cooper. Chelsea was believed to be cheaper than Soho, lacking competition from increasingly affluent residents and mainstream retail and restaurants. In addition, Chelsea's stock of formerly industrial buildings and warehouses offered larger spaces than Soho and thus could accommodate the growing physical dimensions of art (Molotch and Treskon 2008). The conventional wisdom holds that galleries followed artists to Soho, while Chelsea's growth has been driven by preferences of major collectors and dealers (Currid 2007; Thompson 2008). Both commercial galleries and more alternative art venues are still active in Chelsea. The area where most galleries are currently located (between $10^{\text {th }}$ and $12^{\text {th }}$ Avenues, $20^{\text {th }}$ and $26^{\text {th }}$ Streets) has so 
far seen less residential or commercial development than Soho. However, the relatively recent addition of recreational spaces such as Hudson River Park and the High Line Park may draw additional investment.

\section{Section 3) Development of Manhattan Gallery Database}

Large scale quantitative analysis of spatial patterns in the art market has been infeasible because of the lack of reliable data sources on gallery (or studio) locations at a fine level of geographic detail or over long periods of time. The Manhattan Gallery Database offers several significant improvements in data quality over publicly available sources, such as the ZIP Business Patterns or Economic Census. Besides providing exact locations for all galleries from 1970 to 2003, the Manhattan Gallery Database contains some information on gallery differences by firm type and tenure. Specifically, we identify notable or "star" galleries, firms that operate multiple establishments (branches) in the same year, and calculate gallery lifespan. ${ }^{4}$

Data source, collection and cleaning procedures

The original data source for gallery names and addresses is the Manhattan Yellow Pages, obtained from the New York and Los Angeles Public Libraries for each year from 1970 to 2003. The Yellow Pages lists name, street address and phone number for all businesses that pay a small annual fee. Businesses select which category (or categories) they wish to be listed under; we extracted all pages under the heading "Art Galleries". This category excludes museums, which display art but do not sell it, and privately held art collections, but may include some businesses which engage in other activities besides the sale of original artworks, such as framing shops or

\footnotetext{
${ }^{4}$ In accordance with industrial organization terminology, "firm" refers to a corporate entity (i.e. The Gap or McDonald's) while "establishment" or "branch" refers to a specific store (gallery). As discussed below, the overwhelming majority of gallery firms operate only one establishment, in which case the distinction is not necessary. But a small number of firms operate multiple branches or establishments simultaneously.
} 
antique stores. Therefore our inventory may include establishments that would be omitted from data sources such as the ZIP Business Patterns, which ask firms to self-identify industry sector based on primary revenue source. An inverse potential concern is self-selection into the Yellow Pages: galleries that opt not to pay the listing fee will be omitted from the dataset. Because there is no other data source that contains a complete list of galleries, we cannot verify the degree of selection into the Yellow Pages. However, based on the comparison with notable galleries listed in New York City guidebooks (described below), we can infer a very small number of galleries chose never to be listed in the Yellow Pages during the 34 years for which we have data. ${ }^{5}$

From the Yellow Page listings, we assembled an inventory of gallery names and street addresses. The data were subjected to a rigorous cleaning process to correct and standardize addresses, remove galleries located outside Manhattan, and remove duplicate observations. Fewer than 100 observations out of approximately 30,000 were ultimately dropped from the dataset because of missing or incorrect address information. All remaining street addresses (100 percent match rate) were successfully geocoded using ArcGIS. To create a longitudinal database, we linked firms across years by matching gallery names, with addresses used as a secondary criterion. The exact format of gallery names varied somewhat in different years of the Yellow Pages, so researchers visually examined the dataset to assign a common numeric ID to all establishments with the same name. Most gallery names are highly distinctive so matches were very rarely ambiguous, and many galleries also keep the same street address for multiple years, further enabling accurate matching.

Although we have a high degree of confidence that the database captures most galleries that existed in Manhattan at some time between 1970 and 2003, there is a greater probability that

\footnotetext{
${ }^{5}$ One reason for ending the database in 2003 is that in more recent years, a larger share of galleries may have chosen to advertise only online, so printed directories may be biased towards older, more established firms.
} 
some galleries were omitted from the Yellow Pages in any given year. Approximately three percent of the galleries exhibit "gaps" in between listing years; we impute constant location for galleries during gaps up to five years in duration. ${ }^{6}$ Total imputed values are approximately three percent of observations. Assuming that the imputations and gaps are randomly distributed across neighborhoods, they should not introduce bias into subsequent analysis.

Qualitative differences among galleries: Firm type and tenure

A relatively small number of gallery owners are believed to be particularly influential in the art market (Crane 1989; Thompson 2008). Classifying “star" galleries based on artistic quality is an inherently subjective and taste-driven process. However, one measure of commercial importance is the degree to which galleries are known by the general public.

Therefore we used historic New York City guidebooks to compile a list of notable galleries; although guidebooks are not written by art experts, they should flag galleries that have received widespread public and media attention and are relatively accessible to non-experts. Through the New York Public Library, we obtained copies of Fodor's and Frommer's Guides to New York for nine years between 1974 and 2008. No mention of specific gallery names was found in the 1974 guidebook. From 1977 to 1993, the guidebooks list individual gallery names as part of neighborhood walking tours. From 1998 onward, the overall city "Shopping" chapter contains a separate heading for art galleries. There is likely to be some lag in guidebooks' identification of notable galleries, both because of the infrequent updating of guidebooks and the probability of reputation lags. Therefore any gallery that is mentioned at any time is flagged as a star for its entire duration in our database. All but two of the 86 notable gallery names from the guidebooks

\footnotetext{
${ }^{6}$ If a gallery listing with the same name and address occurred in Yellow Pages with up to five years between editions (i.e. 1985 and 1989), we assume that the gallery existed with the same name and address during intervening years. Although median gallery lifespan is three years, it is likely that apparently identical galleries that appear in bookending years continued in between.
} 
also appear in the Yellow Pages, suggesting that the Yellow Pages are a comprehensive and reliable source for commercially important gallery listings. ${ }^{7}$

Besides star status, we observe whether the gallery firms in our database operate multiple establishments in the same year within Manhattan. ${ }^{8}$ Approximately twelve percent of the observations are multiple locations for the same firm in the same year (Table 1). The vast majority of these observations list two addresses in a single year, which could result from duplicate reporting of old and new addresses following a firm's relocation. Fewer than 25 of the approximately 4500 firms have more than two locations per year, or have multiple locations that persist for several years, as would be expected if they were actively pursuing a franchising strategy. However, because we cannot determine the reasons behind the overlap, we flag any firm that lists more than one address in the same year as a multi-establishment firm.

Ideally we would classify all galleries, either by measuring the quality or quantity of art displayed or sold, or by categorizing the type of art. Unfortunately there is no source of such information for galleries. We matched gallery names to guidebooks to identify "stars", but in general gallery names are not a reliable indicator of the type or quality of art. Many galleries use similar naming conventions, such as the gallery owner's name or the address. For a small number of galleries, the name contains some information about the type of art (" $49^{\text {th }}$ Parallel Center for Contemporary Canadian Art"). Some of the names are ambiguous about period or type ("Ancient and Modern Art Gallery") and other names do not even reveal themselves as galleries ("A Fly Can’t Bird But A Bird Can Fly"). Therefore names cannot consistently be used to infer qualitative information about galleries.

\footnotetext{
${ }^{7}$ We used the guidebooks and gallery websites to assemble location information for those two galleries.

${ }^{8}$ A small number of gallery firms located in Manhattan also have establishments outside New York.
} 
Using the longitudinal structure of the data, we calculate the tenure of gallery establishments and firms. For any gallery firm that enters the dataset after 1970 and exits the dataset prior to 2003, we use the first and last years in the dataset to calculate lifespan of the firm. Similarly we calculate tenure of each establishment by using first and last years at the same address. Two caveats should be noted about the tenure data. First, we cannot determine the true tenure for any firm (establishment) that appears in our dataset in 1970 or remains in the dataset as of 2003 (i.e. tenure is potentially left-censored and right-censored). Second, because we only observe galleries located in Manhattan, any firm (establishment) that moves into or out of Manhattan during this time period will have a longer true tenure than we calculate. That is, we identify "births" as the first appearance in the dataset, although the gallery may have existed elsewhere before locating in Manhattan, and we identify "deaths," which may really be moves out of Manhattan. However, given that the median tenure of most firms and establishments is three years, and that most firms do not move, we think that the truncation of tenure will introduce only a small amount of noise into our estimates.

\section{Section 4) Empirical strategy and additional data sources}

We begin by establishing several stylized facts about the Manhattan art market, focusing particularly on the industry structure and spatial patterns of galleries. We then link the gallery database to other data on neighborhood economic, demographic and physical conditions, and use regression analysis to test several hypotheses that could explain the high degree of spatial concentration among galleries.

Descriptive statistics on gallery industry structure and spatial patterns 
To explore the industry structure of the art market, we tabulate the distribution of galleries by firm type. Of particular interest is the prevalence of "star" galleries and multiestablishment firms. Because the Manhattan Gallery Database does not provide information on the size of galleries, we draw on the Census Bureau's ZIP Business Patterns Database to estimate the distribution of galleries by number of employees, another indicator of industry structure. The ZBP counts galleries, art dealers and auction houses as a subset of the retail industry (NAICS 453920). We also calculate the average tenure of galleries, for all galleries and by firm type, as a preliminary indicator of whether changes in spatial patterns over time are more likely to result from movements of existing galleries or turnover through births and deaths. As will be shown below, the median lifespan of galleries is quite short, around three years, yet gallery clusters by neighborhood remain stable over decades. This implies that the continued prevalence of dominant gallery neighborhoods relies on similar location choices of new galleries.

Our primary research objective is to analyze and explain the high degree of spatial concentration among galleries. We begin by mapping the location of galleries across and within Manhattan neighborhoods for selected years. We identify neighborhoods with particularly large numbers of galleries, and explore changes in gallery clusters over the thirty-year time span of the database. As a more formal indicator of clustering, we calculate a standard nearest-neighbor index of clustering, first developed by Clark and Evans (1954) and frequently used in the industrial organization literature (Dixon 2001; Fischer and Harrington 1996; Picone et al 2009). The equation for the index is shown below:

$$
\overline{D_{\min }}=\frac{\sum_{j=1}^{n} \operatorname{Min}\left(d_{i j}\right)}{n}
$$

In brief, $d_{i j}$ is the pairwise distance between each gallery (i) and all other galleries ( $\mathrm{j}$ ) that exist in the same year. Selecting the five nearest galleries $(n=5)$, as indicated by the literature, we then 
calculate the average distance to those five galleries. Increasing values of the index indicate greater average distance to nearby galleries, or lower concentration. One limitation of a galleryto-gallery nearest neighbor index is that it does not allow us to compare concentration at the neighborhood level. For instance, about half of all census tracts in Manhattan have no galleries in a given year, so the gallery-to-gallery index cannot be calculated for these tracts. To obtain an equivalent tract-level measure of concentration that is valid for tracts with and without galleries, we calculate a variation on the index, using the distance from the geographic center of each tract to the five nearest galleries (which may be inside or outside tract boundaries). These metrics of gallery concentration will be used in regression analysis to indicate whether location choices of new galleries are affected by existing gallery density.

What factors affect gallery location choice?

Having established that galleries exhibit a high degree of spatial concentration, we test several hypotheses that could explain the observed spatial patterns. One hypothesis is that galleries cluster together to benefit from agglomeration economies, as suggested by theoretical models of retailers that offer expensive, quality-differentiated products. If this hypothesis is correct, we would expect newly opening galleries to locate near existing galleries or in neighborhoods with a high density of existing galleries. Another, slightly more indirect test of agglomeration economies is to examine whether galleries locating near other galleries are more successful in that they have longer lifespans than spatially isolated galleries.

A second hypothesis is that galleries co-locate in order to share access to common amenities or resources, such as proximity to potential consumers or complementary businesses. We draw on several strains of previous literature to determine the types of resources that might attract galleries. Certain characteristics of the physical environment or geography might be 
assets to galleries: museums may attract art enthusiasts, employment centers have higher volume of visitors more generally, while the vintage and cost of buildings may affect the suitability of space for galleries. Demographic and economic characteristics of the population could also play a factor in galleries' location choices, although prior literature offers competing views of how these characteristics might matter. Retail location models suggest that galleries, as purveyors of luxury goods, should locate near concentrations of affluent potential consumers. By contrast, the cultural industries literature and neighborhood case studies suggest that galleries prefer to locate in proximity to artists and a bohemian social milieu. Because we do not have the data to compare neighborhoods by residents' occupation or industry mix, we use several demographic and economic characteristics to proxy for concentrations of up-and-coming artists and other bohemian occupations. In particular, we predict that bohemian neighborhoods will have lower average income, lower rent, higher shares of young adults and more non-family households (Comunian et al 2010). Not all neighborhoods with these characteristics will be home to concentrations of artists, however; the four traits we identify should be considered as necessary but not sufficient conditions to be classified as bohemian neighborhoods. ${ }^{9}$

Our empirical strategy to test these hypotheses is to model the probability of new galleries locating in a given census tract as a function of baseline tract characteristics. We model newly opening gallery location choices by estimating regressions of the following form:

(Eq. 2) $N E W G A L L_{i t, t+2}=\beta_{0}+\beta_{1} L_{A G G A L L_{i t-1}+\beta_{2} E_{N V I R O N} i t-1}+\beta_{3} P O P_{i t-l}+\beta_{4} N H O O D_{j}+\beta_{5} Y_{E A R_{t}}+\varepsilon_{i t}$ where $\mathrm{i}, \mathrm{j}$ and $\mathrm{t}$ index the census tract, neighborhood and year, respectively. NEWGALL is an indicator of whether new establishments opened in a given tract over a three year period (1971-

\footnotetext{
${ }^{9}$ According to 2006-2009 American Community Survey data, the median income of those in the arts, design, entertainment, sports and media occupations for Manhattan was \$53,093., well below the average income for tracts in which new galleries located $(\$ 89,809)$. National data analyzed by the National Endowment for the Arts (2011) shows that fine artists, art designers and animators earn approximately 80 percent of the annual income for artists in general, meaning that $\$ 53,093$ overstates earnings by this subcategory. While some high income neighborhoods certainly have artists, we are skeptical that artists predominate in those neighborhoods.
} 
$73,1981-83,1991-93,2001-2003)$ as function of tract characteristics in the baseline year (1970, 1980, 1990, 2000). ENVIRON is a vector of variables describing tract physical environmental characteristics, POP is a vector of population demographic and economic characteristics. NHOOD is a set of fixed effects for neighborhoods, using the Department of City Planning definitions described below; YEAR is a set of year fixed effects. Specific variable definitions and sources are shown in Table 4.

Several features of the empirical strategy help identify whether gallery location patterns are associated with agglomeration effects and neighborhood characteristics. First, we focus on movements of new establishments because these are marginal firms, making conscious decisions about where to locate based on current market conditions. ${ }^{10}$ Second, the inclusion of neighborhood fixed effects allows us to test for gallery location choice across tracts within the larger neighborhood (i.e. Soho or the Upper East Side). These fixed effects will absorb observed and unobserved characteristics that are the same for all tracts within the neighborhood and are constant over time, such as a neighborhood's reputation as a cultural center or shopping destination. ${ }^{11}$ Third, we include a range of tract-level characteristics that could directly or indirectly influence gallery location choice across tracts within the larger neighborhood.

Some caveats remain about whether our results should be interpreted as identifying causal relationships, however. If we have omitted tract-level factors that are correlated with new gallery location choice and with any of our included explanatory variables, the omitted variables will create bias in our estimated coefficients. For instance, suppose that galleries are attracted to certain types of commercial activity, such as other luxury stores or trendy nightclubs. If certain

\footnotetext{
${ }^{10}$ Seventy-two percent of newly opening galleries in Manhattan are new firms, with the remainder being expansions or relocations of existing firms.

${ }^{11}$ Robustness checks including neighborhood-year fixed effects, which allow the neighborhood-specific effects to vary over time, yield highly similar coefficients on independent variables. Results available from authors upon request.
} 
tracts have historically had high concentrations of stores and nightclubs, those tracts are likely to have a high density of galleries in the baseline year. The estimated coefficient on baseline gallery density will reflect both the effect of existing galleries and the effect of (unobserved) commercial activity, leading to an upward bias on the true impact of gallery density. (In this example, the estimated coefficient on tract income would also likely reflect an upward bias). It is not feasible to assemble tract-level historical data on all the possible amenities that could influence gallery choice, nor is it possible to test empirically the degree of bias in our estimates. But most Manhattan neighborhoods are economically and demographically quite dynamic, especially over a thirty year period, suggesting that tract-level amenities that affect gallery location choices are likely to have evolved over our study period. Nonetheless, our coefficients should be interpreted as evidence of associations between new gallery location choice and specified tract characteristics, but not necessarily proof of causal relationships. ${ }^{12}$

The distribution of the dependent variable requires careful consideration of functional form and estimation technique. The count of new galleries is highly skewed; more than half the tracts have zero galleries, while a small number of tracts have many galleries. Our preferred model is a probit specification, which estimates the probability of any new gallery in the tract conditional on neighborhood characteristics. Formally, the probit specification is given by $\operatorname{Pr}(Y=1 \mid X)=\varphi\left(X^{\prime} \beta\right)$ where $\mathrm{Y}$ is the outcome, $\mathrm{X}$ is a vector of explanatory variables, $\beta$ is a vector of parameters, and $\Phi($.$) denotes the standard normal distribution. The log-likelihood$ function for the probit model is

$$
\text { (Eq 3) } \quad L=\sum_{y_{i}=0} \ln \left[1-\varphi\left(X_{i}^{\prime} \beta\right)\right]+\sum_{y_{i}=1} \ln \varphi\left(X_{i}^{\prime} \beta\right)
$$

\footnotetext{
${ }^{12}$ Another approach to controlling for time-invariant tract characteristics would be to include tract-level fixed effects. However, because roughly two-thirds of the tracts have constant values for the main dependent variable, the presence of any new galleries, during our four time periods, including tract fixed effects in a probit model does not allow valid first order conditions. Estimates of OLS models on the logged number of new galleries per tract with census tract fixed effects gives generally consistent results to those shown in Table 7.
} 
where $\mathrm{y}_{\mathrm{i}}$ and $\mathrm{x}_{\mathrm{i}}$ are the observed values of outcome $\mathrm{Y}$ and explanatory variables $\mathrm{X}$ for observation i (Greene 1993). The other preferred specification is a Tobit model estimating the natural logarithm of the number of galleries, correcting for left-censored observations at zero (McDonald and Moffit 1980). The Tobit specification makes the best use of the upper-end variation in the number of galleries (i.e. the small number of tracts with many new galleries). We also estimate several robustness tests with the probit model, stratifying the sample to compare neighborhoods with a small number of new galleries to those with many (0-4 galleries relative to $5+, 1-4$ relative to $5+, 0$ compared to $1-4)$. Results on the main independent variables (prior gallery presence, income and rent) are largely consistent across these specifications. ${ }^{13}$

Similarly, we estimate models with several difference metrics of prior gallery presence. The simplest version is a dummy variable indicating the presence of any gallery in the tract in baseline year (ANYGALL). About half of tracts in any year have zero galleries. Because tract boundaries are somewhat arbitrary, this indicator draws no distinction between tracts that contain no galleries but are near gallery clusters in other tracts and tracts that are located far from any galleries. Therefore a better metric is the tract-level nearest neighbor index, described above. Robustness checks using other measures of prior gallery presence - number of galleries, log number of galleries, number of star galleries - yield nearly identical regression results (available from authors upon request).

Besides the baseline model, location choice of any new gallery, we consider differences in location decisions for star and multi-establishment galleries. It is possible that new star galleries have greater flexibility in location choice, if they generate their own business rather than relying on neighborhood reputation or proximity to fixed amenities like museums. If star and non-star galleries sell art at different price points or different genres, they might also choose

\footnotetext{
${ }^{13}$ Full results available from authors upon request.
} 
to locate in neighborhoods with different demographic or economic characteristics. The same may be true of multi-establishment galleries. Unfortunately regressions are of limited help in analyzing location choice by firm type because of the small number of observations with new star or multi-establishment galleries, therefore our analysis by firm type is limited to difference in mean characteristics.

\section{Survival analysis: Does proximity to other galleries affect longevity?}

If galleries are strategic about choosing location to maximize profits, then we would expect location characteristics to affect probability of survival. In particular, if galleries cluster to benefit from agglomeration economies, proximity to other galleries should increase the flow of consumers and improve the volume of business, relative to more isolated galleries. Therefore we estimate hazard rates as a function of proximity to other galleries, using the tract-year as the level of observation. Specifically, we use a Cox proportional hazard model to estimate the likelihood of death for firm (establishment) $i$ occurring between $t$ and $\Delta t$, given that the firm (establishment) exists in time $t$. The hazard rate at time $t$, the hazard rate, $h_{i}(t)$, is understood as the unobserved rate at which death occurs, and $1 / h_{i}(t)$ is the expected lifespan of the firm (establishment), using the first appearance of each firm (establishment) as the point of origin. The partial likelihood of the Cox model is a flexible estimation option, because it allows for an unspecified form for the underlying survivor function as well as inclusion of time-varying and time-invariant explanatory variables. The equation to be estimated is:

$(E q 4) \quad h_{i}(t)=\lambda_{0}(t) \exp \left(G A L L_{j t}, F I R M T Y P E_{i}, P U M A_{i}, Y R_{t}\right)$

In this regression, $\lambda_{0}(\mathrm{t})$ is the baseline hazard function for a firm (establishment) with all covariates set to 0 . Subscripts $i, j$ and $t$ index the firm (establishment), census tract and year, respectively. GALL is a vector of variables indicating the presence and concentration of other 
galleries in the tract; this varies by tract and year. FIRMTYPE indicates the type of firm - star, multi-establishment non-star, or single-establishment non-star - for each firm (establishment) and does not vary over time for the establishment. As noted previously, most gallery firms operate only one establishment at a time, and indeed most firms have only one establishment over the firm lifespan. However, for firms with multiple locations, either in the same year or successive years, the firm and establishment lifespans will differ. By estimating models separately for establishments and firms, we can test which factors affect the longevity of a gallery at a particular location (establishment) relative to the firm lifespan, which may include multiple locations. Models also include fixed effects for PUMA and year. ${ }^{14}$

Cox proportional hazards models are also useful for dealing with censored data. As our data collection ends in 2003, any firm (establishment) still in existence in that year is not observed to die during the study period. Approximately 86 percent of establishments and 81 percent of firms have observed deaths during out study period (exit the dataset prior to 2003), so the estimation must include and account for the remaining censored observations. Results for each model report the number of subjects and failures in that estimation.

\section{$\underline{\text { Additional data sources }}$}

In addition to the Manhattan Gallery Database, our analysis uses a variety of public data sources. Tract level data on demographic and economic characteristics is obtained from Geolytics' Neighborhood Change Database, which provides data for geographically constant census tract boundaries from 1970-2000. Specific variables of interest include population density, income, educational attainment, race/ethnicity, age distribution and household type; rent

\footnotetext{
${ }^{14}$ Some models include tract environmental and population characteristics as controls, but the estimates on those variables themselves are not reliable or meaningful. Hazard models only include tracts that have one or more galleries, about one-third of tracts per year. Because galleries do not locate in typical tracts, there is limited variation in control characteristics.
} 
and age of housing stock. ${ }^{15}$ We also use the latitude and longitude for the centroid of each census tract to calculate the distance to the Empire State Building, a proxy for the Central Business Distrct (CBD). ${ }^{16}$ Data on the location and opening years of most major museums in Manhattan were assembled from the 2006 Rough Guide to New York and various museum websites. Variable definitions are shown in Table 4; summary statistics are shown in Appendix Table B.

Although our regression analysis is estimated at the census tract level, tracts are much smaller than the informally defined neighborhoods, such as Soho or the Upper East Side, that are referred to in the qualitative literature. Manhattan census tracts are approximately 4-8 city blocks in length and/or width, as shown in Figure 2. For the descriptive statistics, we use neighborhood definitions designated by the NYC Department of City Planning; DCP aggregates geographically contiguous clusters of census tracts into larger neighborhoods that share the colloquial neighborhood names. ${ }^{17}$ The number of tracts per DCP neighborhood varies from 2 to 15, so population and geographic size also vary considerably. The list of 2000 census tracts assigned to each DCP neighborhood is shown in Appendix Table A.

\section{Section 5) Empirical Results}

Descriptive statistics: Industry structure and tenure

The New York art market is dominated by independent and relatively unknown firms.

Fewer than two percent of the firms and about four percent of establishments belong to identified

\footnotetext{
${ }^{15}$ We use rent rather than price as a measure of housing costs, because a large majority of housing units in Manhattan are renter-occupied. Also the Census estimate of value for specific owner-occupied units prior to 2000 is derived only from single-family detached, non-condominium units, of which there are very few in Manhattan.

${ }^{16}$ In 1982, the Economic Census designated Midtown (from $28^{\text {th }}$ Street up to $59^{\text {th }}$ Street and including the Empire State Building) as the CBD. http://www.census.gov/geo/tiger/cbdct.pdf

${ }^{17}$ http://www.nyc.gov/html/dcp/html/bytes/meta_pa.shtml.
} 
star galleries (Table 1). The number of firms that franchise is also small: 6.4 percent of firms and twelve percent of establishments. At any point in time, no firm had more than six establishments, with a mean of 1.2 establishments per firm in the same year, indicating that even among firms that ever franchise, operating multiple establishments in the same year is quite rare. As might be expected of an industry dominated by independent entrepreneurs, most galleries are small. According to the Census Bureau's ZIP Business Patterns data for 2000, 76 percent of Manhattan galleries have fewer than four employees. Firm structure does vary by star status: 30.2 percent of star firms have multiple establishments at some point in their existence, compared to 3.4 percent of non-star firms, but even the star firms have a small number of franchises, compared to chain store standards in other retail sectors. It is unclear whether being recognized as a "star" by a guidebook will lead to more business success, thus enabling expansion, or whether guidebooks are more likely to know of and recommend more prevalent galleries. $^{18}$

Like other segments of the retail market dominated by independent firms, turnover in the gallery business is fairly high. The median tenure for both firms and establishments is only three years (Table 2). Both non-star, multi-establishment galleries and star galleries have longer tenure than non-star, single-shop galleries — of course it is not clear whether star status leads to longer tenure, or whether long tenure produces star status. Of the 62 firms that survived the entire study period, 42 are non-star, non-franchised firms. The high rate of turnover among individual galleries raises the possibility that overall gallery concentrations or "hot spots" might change quickly, although examination of spatial trends over time indicate that this is not the case.

\footnotetext{
${ }^{18}$ Crane (1987) found that artists represented by "gatekeeper" galleries were disproportionately more likely to have their work acquired by museums or to be given a major exhibition.
} 
Whether tenure is affected by proximity to other galleries, as would be expected under agglomeration economies, will be explored more thoroughly using hazard models.

\section{Descriptive statistics: gallery spatial patterns}

Consistent with anecdotal evidence from neighborhood case studies, art galleries in Manhattan exhibit a high degree of spatial clustering. Figure 1 shows that in 2000, galleries clustered on the east side of Central Park (the Upper East Side), along $57^{\text {th }}$ Street in Midtown, and in the downtown areas of Soho and Chelsea. Galleries are even tightly clustered along certain blocks within neighborhoods; Figure 2 shows the location of galleries within Soho in 1990, close to its peak year. Just one census tract has half the galleries in Soho, and within the Upper East Side, three census tracts have more than half the galleries. Table 3 demonstrates that from 1970 to 1990, the top three neighborhoods contained over 60 percent of Manhattan galleries (in 2000 the top three neighborhoods' share dropped to about 55 percent). More than half Manhattan's galleries are located in just 1.2 percent of the borough's census tracts, and more than half the tracts in Manhattan have no galleries in any year from 1970-2003. Star galleries are even more highly concentrated in the dominant neighborhoods (though are not exclusively located there), but within those neighborhoods, the vast majority of galleries are not stars.

To quantify the degree of clustering, we calculate the nearest neighbor index, measuring the average distance from each gallery to its five closest galleries, at the beginning of each decade. Index values range from zero (a gallery shares an address with five or more galleries) to four miles, with an average of 0.07 , indicating that the average gallery is located less than onetenth of a mile from five other galleries, a very narrow proximity. In Manhattan, north-south blocks are approximately 0.05 miles, cross-town blocks are approximately 0.17 miles. Therefore 
galleries are on average located within two uptown blocks or half a cross-town block of their five nearest neighbors. There is no apparent time trend in average distance between galleries.

With a few small deviations, total galleries in Manhattan grew over the sample period until 2001, at which point the number dropped fairly sharply. But rate of growth by neighborhood varies widely over the sample period (Table 3). The number of galleries in established neighborhoods (the Upper East Side, East and South Midtown) gradually declines, while Soho saw a major increase beginning in 1980 and Chelsea saw a major increase beginning in 1997. Greenwich Village also saw a gradual decline in the number of galleries, and the East Village saw a small spike in the late 1980s before reverting to previous levels.

Despite fluctuations in the number of galleries within neighborhoods, the rankings of neighborhoods remain remarkably stable over long periods of time. All top five neighborhoods from 1970 remain in the top ten throughout our study period (Table 3). The Upper East Side had the most galleries of any Manhattan neighborhood nearly every year, although Soho essentially tied with it during the 1990s: these two neighborhoods were clearly the dominant locations of the art market in Manhattan. Greenwich Village, which was the original "avant-garde" gallery neighborhood, has a fairly small gallery presence, although still ranking fifth among the borough's 39 neighborhoods. The East Village, which attracted considerable attention for its bohemian reputation, never ranks in the top five neighborhoods. The evolution of most gallery clusters does not seem to be explained by relocations of existing firms. Only 3.8 percent of gallery firms move at any point, and only 2.5 percent move from one neighborhood to another.

The rapid evolutions of first Soho and then Chelsea have been quite unusual, relative to more gradual changes in other neighborhoods. The number of galleries in Soho increased more than tenfold, from 5 to 58, between 1970 and 1975, and then quadrupled over the following 15 
years. The number then fell by half between 1995 and 2003. Chelsea had a small, slowly growing base of galleries for the first two decades of the study - starting at 13 in 1970 and rising to 34 in 1995 - then doubling to 67 in 1997 and again to 133 in 1999, before peaking at 201 in 2002. Like Soho and Manhattan as a whole, Chelsea saw its numbers drop sharply in 2003 (from 201 to 176 in a single year). Explaining the reasons for the relatively volatile growth and decline in these two neighborhoods is beyond the scope of this paper, but we can offer a few comments. Some media observers (Kennedy 2006) have suggested that Soho declined as a result of a drop in global art prices in 1989-1992; this seems an unlikely explanation, given that the drop in Soho's numbers began in 1997, a lag of nearly twice the average gallery lifespan. The decline in galleries across most neighborhoods, and Manhattan as a whole, in the last two years of our dataset may reflect the post-September 11 recession (very few galleries have ever located in Lower Manhattan, so the destruction of the World Trade Center and surrounding area did not directly cause the loss of galleries). ${ }^{19}$

Descriptive statistics: What factors influence gallery location choice?

We now move to examine several hypotheses behind the high degree of gallery concentration. In particular, do galleries seek to locate near other galleries? Are they independently drawn to certain neighborhoods to take advantage of location-specific amenities, and if so, what amenities do they seek?

To begin with, we compare differences in baseline characteristics between neighborhoods in which at least one new gallery opened and neighborhoods with no new galleries (Table 5). This simple analysis suggests that neighborhoods into which new galleries move differed along baseline characteristics, including presence of prior galleries, physical environment, and

\footnotetext{
${ }^{19}$ We cannot rule out the possibility that galleries switch from advertising in the Yellow Pages to using online advertising during this period. However, it seems unlikely that this switch would occur so suddenly.
} 
population characteristics. Tracts with at least one new gallery had a larger number of preexisting galleries and higher density of galleries (shorter average distance). New gallery tracts had a higher museum density, were closer to the CBD, and had older housing stock. Perhaps somewhat surprisingly, new galleries moved into tracts with average baseline rent $\$ 335$ higher than tracts that did not receive new galleries - an initial rent premium of more than 50 percent. Average household income in gallery tracts was $\$ 41,512$ higher (85 percent) and the share of college-educated population was double that of non-new gallery tracts (48 percent compared to 24 percent). Gallery tracts had slightly lower population density, a larger share of white population and a higher share of non-family households. New gallery tracts were also initially older, with half the share of residents under age 18 .

The evidence from this preliminary analysis therefore suggests that both agglomeration economies and differential access to amenities may drive gallery location decisions. Proximity to the CBD and museums are consistent with location-specific amenities that could boost the volume of visitors to art galleries. Older housing stock may be a proxy for building or architectural quality: in large cities with high redevelopment potential, the fact that a building survives many decades can reflect that it is a high quality building, or was built in an era with desirable architecture (Chang et al 2005, Rosenthal 2008). The results on demographic and economic characteristics are consistent with predictions of retail location models: stores selling expensive luxury goods prefer to locate near high-income, highly educated potential consumers. Given existing income and wealth discrepancies by race in the U.S., it also seems plausible that potential art collectors are more likely to be white. The difference in rent could be open to multiple interpretations. Although galleries (like most businesses) presumably prefer to pay lower rents, all else equal, galleries may also value locally specific amenities that are capitalized 
into rent. One possible interpretation is that when faced with a choice between high-amenity, high-rent neighborhoods and low-amenity, low-rent neighborhoods, galleries choose the former. Because we are looking at location choices of newly opening galleries, it is not possible that the higher rent results from those galleries' presence. Regression analysis will help identify whether high rent discourages new galleries, conditional on amenities such as proximity to the CBD and resident demographics. Support for the hypothesis that galleries locate in bohemian neighborhoods is somewhat ambiguous. As expected, new galleries locate in neighborhoods with more young residents (18-34 years) and more non-family households than non-gallery neighborhoods. But the direction of the differences on rent and income runs counter to the hypothesis: it seems unlikely that up-and-coming artists and other bohemians have unusually high incomes and can afford to live in high rent neighborhoods.

As a further check on the relationship between gallery presence and neighborhood economic status, we divide census tracts into deciles by average monthly rent and examine the prevalence of galleries across rent deciles (Table 6). ${ }^{20}$ This allows us to test whether gallery clusters appear at different price levels, for instance, perhaps small groups of avant-garde galleries form in low-to-mid rent tracts while established galleries cluster in the most expensive tracts. Table 6 shows no evidence in support of gallery clusters at multiple rent levels: all measures of gallery presence show monotonically increasing relationships with rent. The share of tracts with at least one new gallery increases at higher rent deciles: fewer than 10 percent of the lowest rent tracts have new galleries, rising to just over 71 percent of tracts in the $8^{\text {th }}$ rent decile, then declining slightly in the highest two deciles. The patterns are similar when looking at distribution of existing galleries: the mean and median number of galleries per tract increases

\footnotetext{
${ }^{20}$ Similar analysis of gallery locations by rent decile for each year, and using income rather than rent, yields virtually identical results.
} 
moving up the rent distribution. Existing galleries are quite scarce in low-rent tracts, with fewer than 15 percent of tracts in the bottom three deciles having at least one gallery, compared to over 80 percent of tracts in the highest three deciles. Among tracts with at least one existing gallery, the number of galleries per tract increases with rent: low-rent gallery tracts have on average 1.25 galleries, compared to 8.32 galleries in the highest rent tracts. We do not have data that would allow us to examine qualitative differences between the few galleries in low-rent tracts and the much larger number in high-rent rents - for instance whether the galleries in low-rent tracts display more avant-garde art - nor is the sample large enough to estimate systematic differences in location patterns for the cheapest tracts. But the evidence strongly suggests that galleries are an unusual feature of low-rent tracts, and quite a common feature of high-rent tracts.

Comparing neighborhoods with new galleries for different gallery types - star versus non-star, multi-establishment versus single-establishment - yields substantively similar results, although fewer significant differences (Table 7). Tracts with at least one new star gallery have a larger number and higher density of existing galleries than tracts with only new non-star galleries. New multi-establishment galleries also locate in more gallery-dense tracts, relative to single-establishment galleries. Tracts with new stars have higher rents, lower population densities, higher incomes, larger white population share, fewer 18-34 year olds and more residents 55 and older, compared to tracts with new non-star galleries. Except for population density, these results are all consistent with luxury retailer models, and directly counter to the bohemian hypothesis. One possibility is that star galleries sell more expensive art than non-stars. Tracts with new multi-establishment galleries have higher museum density, higher income, larger white population share, fewer residents under age 35 and more residents over age 55, also consistent with luxury retail location models. It should be noted that only 31 observations 
(approximately eight tracts per period, over four periods) have at least one new star gallery. The small number of observations makes it more difficult to identify statistically significant differences. For the same reason, multivariate regression analysis of location choice by firm type is of limited usefulness. ${ }^{21}$

$\underline{\text { Regression results: Roles of agglomeration and amenities in gallery location choice }}$

Regression analysis of new gallery location choices confirms many of the results from the differences in means (Table 8). Columns 1-4 show results of probit models, estimating the probability of at least one new gallery as a function of prior gallery presence, environmental and population characteristics. Column 5 shows results of a Tobit model on the natural log of new galleries, adjusting for left censoring at zero.

Consistent with the hypothesis of agglomeration economies, prior gallery presence is associated with a higher probability of a new gallery opening (Column 1). The coefficient on presence of any prior gallery is positive and strongly significant, while the coefficient on gallery density index is negative and significant, indicating that increasing distance from the tract to other galleries is associated with decreased probability of a new gallery opening. The model includes neighborhood fixed effects, so the estimated coefficients imply that new galleries are more likely to select a census tract within the same neighborhood (Soho, Midtown) if the tract already has at least one gallery and has a higher density of existing galleries.

Columns 2 and 3 examine the relationship between physical environment and population characteristics, respectively, on gallery location choice. Including only physical characteristics (Column 2), the probability of a new gallery opening decreases with distance from the tract to museums (or increases in density of museums), and decreases with distance to the CBD.

\footnotetext{
${ }^{21}$ Probit models estimating the location choice of new star and multi-establishment galleries, similar to those shown in Table 7, indicate a significant positive relationship between number of existing galleries and the probability of new galleries for both firm types, but otherwise few significant factors. Results available from authors on request.
} 
Residential rent and older housing share are both positively associated with the probability of a new gallery, consistent with the difference in means shown in Table 5. Some of the coefficients on demographic and economic characteristics confirm the findings from differences in means, while others flip signs (Column 3). Population density is positively associated with probability of new galleries, once other population characteristics are controlled for, a change from Table 5. Regression results confirm that new galleries are more likely to locate in tracts with higher household income, larger white population share and more non-family households. The estimated coefficient on share of college-educated residents becomes negative once other population characteristics are controlled for (in particular income, which is strongly positively correlated with college-educated share). The probability of new galleries choosing tracts decreases with shares of children and older residents, compared to residents aged 35-54, but the coefficient on young adults (18-34) is not significant.

Adding environmental and population characteristics to the agglomeration metrics does not substantially alter the estimates on prior gallery presence (Column 4). The magnitude of the coefficients on the existing gallery dummy and the gallery density index drop slightly but both remain significant at the one percent level. That is, when choosing between two tracts with similar economic, demographic and physical characteristics and located within the same neighborhood, a new gallery is more likely to pick the tract that has a stronger presence of existing galleries. In the combined model, most of the physical environment variables become insignificant (museum density index, distance to CBD and pre-1940 housing share). The coefficient on rent is still positive and significant, even when population characteristics and environmental amenities are added. Rent does not appear to be a deterrent to new gallery location choice, contrary to anecdotal evidence. Several of the population characteristics remain 
significant with the addition of agglomeration measures and environmental variables: the probability of new galleries increases with household income, white population share and nonfamily households, and decreases with college educated share. The positive coefficient on income implies that higher income tracts within larger neighborhoods are more likely to attract new galleries, controlling for prior gallery concentration, physical and demographic characteristics.

The final column in Table 8 offers a robustness check on the model specification, using a Tobit estimation on the natural log of galleries and correcting for left-censoring at zero. While the probit models estimate the probability of any new gallery in the tract, the Tobit model exploits the variation in the number of new galleries. The sign and significance on most coefficients is quite similar between the complete probit model (Column 4) and the Tobit model (Column 5). Prior gallery presence and higher existing gallery density (lower distance to nearby galleries) are associated with a larger number of new galleries, across tracts within the same neighborhood. Most of the coefficients on physical, economic and demographic characteristics are similar as well, including rent, income, education and household type. A few variables that were not statistically significant in the probit model achieve weak significance in the Tobit model (museum density, pre-1940 housing, and population density); this may suggest that these characteristics differ more across tracts with few galleries and those with a large number of new galleries. But the comparison of Columns 4 and 5, together with robustness checks described in Section 3, provide remarkably consistent evidence on the main results across a variety of estimation techniques and sampling frames. ${ }^{22}$

\footnotetext{
${ }^{22}$ Estimation using OLS, probit and Tobit techniques all produce largely similar results. Inclusion of fixed effects using various definitions of neighborhood (PUMA, DCP neighborhood, neighborhood-year) also does not materially change the results on the agglomeration variables or key population and environmental variables.
} 
In summary, our results suggest that agglomeration economies play a role in gallery location choice, and are highly consistent with luxury retail location models. Recent empirical studies suggest that retail density increases with population density, household income, and white population share, but decreases in educational attainment (Meltzer and Schuetz 2012, Schuetz et al 2012). By contrast, the results are not consistent with the hypothesis that galleries are seeking out neighborhoods with up-and-coming artists or other bohemians. Of the four variables that proxy for bohemian neighborhoods, income and rent are significant in the wrong direction, share of young adults (18-34) is insignificant, while only non-family household share is significant in the expected direction.

\section{$\underline{\text { Survival analysis results: Does gallery concentration affect lifespan? }}$}

We turn last to another test of agglomeration economies: does proximity to other galleries affect own gallery lifespan, either at the establishment or firm level? As shown in Table 2, the median firm and establishment has a lifespan of three years, but a small number of galleries endure the entire stretch of our dataset, and longevity appears to vary by firm type. Figures 6-7 illustrate the variation in longevity by firm type. Table 9 shows the results of hazard models, first for establishments (Columns 1-3) and then for firms (Columns 4-6). The difference between establishment and firm level models is relevant for firms that operate multiple establishments, either simultaneously or in succession.

The results of survival analysis are again supportive of agglomeration economies. Galleries in tracts with a larger number of other galleries, and a higher density of galleries, are less likely to die (exit the dataset) in any given year. The coefficient estimates are highly robust for both establishments and firms across various models, including controls for firm type (Columns 2 and 5) as well as neighborhood environmental and population characteristics 
(Columns 3 and 6). Proximity to other galleries appears to improve at least one performance measure, namely, the length of time a gallery stays in business. Results also confirm that gallery longevity varies by firm type. Establishments and firms belonging to star galleries have lower risk of dying than non-star galleries. The main difference between the firm and establishment hazard models is that, while franchising status does not affect establishment tenure among nonstars, multi-establishment firms have longer lifespans than single-establishment firms. This result suggests that multi-establishment firms survive in part by moving to different locations. The pattern in which multiple establishments occur is consistent with a firm opening a second location, operating both galleries for 1-2 years, then closing the less successful location.

\section{Section 6) Conclusions and future research}

Cultural institutions, such as art galleries, museums and performance venues, are generally considered to be valuable amenities to a neighborhood and a city, capable of attracting tourists and enhancing the quality of life of urban residents. New York City is home to worldfamous arts institutions, such as the Metropolitan Museum of Art and Lincoln Center, but also to a large number of more modest neighborhood galleries. Over the past half century, a handful of New York's neighborhoods have become well-known for their concentrations of artists' studios, galleries, and affiliated nightlife. Qualitative case studies have described the evolution of several neighborhoods, notably Soho and Chelsea, which provide some hypotheses about what factors attracted galleries to these neighborhoods. The goal of this paper is to provide a larger context for these neighborhoods and test several hypotheses that could explain gallery location patterns. Our newly developed dataset of Manhattan galleries allows us to make several improvements over previous research. We use a larger geographic area (all of Manhattan, rather than one or 
two neighborhoods) and examine the evolution of gallery locations over 34 years. Our research design compares census tracts with and without newly opening galleries to systematically test the relationships between prior gallery presence, as well as physical, economic and demographic characteristics, and gallery location choices. To our knowledge, this is the first study to conduct relatively large-scale quantitative analysis of the art market, moving beyond anecdotal evidence to test the conventional wisdom that galleries locate in economically marginal "bohemian" neighborhoods.

Examining the structure of the retail art market reveals that the industry is composed mostly of small, independently owned firms, with a small number of "star" galleries and franchising firms. Galleries are highly spatially concentrated, with a few neighborhoods dominating the market. Growth and decline of gallery clusters occurs asymmetrically: the number of galleries in a given neighborhood can grow rapidly in a short period of time, but once a neighborhood has an established cluster, decline occurs slowly. The rise of Soho in the 1970s and 1980s and the growth of Chelsea in the late 1990s were unusually rapid among Manhattan neighborhoods. New galleries are more likely to locate in neighborhoods with existing gallery clusters, and proximity to other galleries increases longevity. Both of these results strongly suggest that galleries benefit from agglomeration economies. Galleries tend to locate in census tracts with high rent, high household income, and a larger white population share, consistent with the behavior of luxury retailers. Our results are not consistent with the hypothesis that galleries locate in "bohemian" neighborhoods, as indicated by several demographic and economic variables. Environmental amenities such as proximity to the $\mathrm{CBD}$ or museums appear to be at most marginal factors in gallery location choice. 
A limitation of our analysis is that we cannot directly measure all of the amenities that might play a role in galleries' location decisions. Notably, we have no data on the location of artists' residences or studios, or on potentially complementary commercial activity, such as coffeeshops, nightclubs or other types of retail. To the extent that these omitted variables are correlated with gallery location choice and with our independent variables, our coefficient estimates may be biased. As discussed previously, the direction of our proxies for "bohemian" neighborhoods cast doubt on whether galleries do co-locate with up-and-coming artists, but the omission of artists from the regressions may bias our estimates on the demographic and economic variables. Omission of commercial activity may introduce upwards bias in our estimates on the agglomeration variables: if previous galleries selected certain tracts because of strong commercial presence, and new galleries choose these tracts for the same reason, then our estimated coefficient on previous gallery density will confound the two factors. The inclusion of neighborhood fixed effects, and the long time span of our analysis in a highly dynamic city, mitigates but does not eliminate the concern over endogeneity.

If the evidence we find of agglomeration economies is accurate, however, that may explain the remarkable persistence of gallery clusters over time: all the neighborhoods that ranked in the top five gallery counts in 1970 remain in the top ten thirty years later. Even though art historians perceive that the Upper East Side and Midtown have waned in artistic importance relative to Soho and Chelsea, the older neighborhoods continue to have large concentrations of galleries and to attract newly opening establishments. Agglomeration economies imply a degree of path dependence, which may explain some of the difference in gallery concentrations across economically similar areas (for instance, why the Upper East Side dominates in galleries while the similarly affluent Upper West Side has relatively few). 
Our results suggest several areas that would be profitable for further research. Is there a critical mass of galleries that is required before agglomeration economies come into play? The Manhattan Gallery Database could be used to examine changes in number of galleries against larger time trends, such as fluctuations in the stock market, to determine whether particular neighborhoods or types of galleries are more affected by broader economic dynamics. We would expect that galleries selling higher value art would be more vulnerable to changes in household wealth. For a restricted set of years, combining the gallery database with ZIP Business Patterns would allow analysis of what businesses are complementary to galleries - for instance, do galleries co-locate with certain types of retail, restaurants, or entertainment venues?

Our analysis focuses on Manhattan, which is an unusual setting among U.S. cities in many ways, including the size and prominence of the art market. Thus some of the implications, particularly with regard to star galleries, will be most relevant for other global art agglomerations such as London, Paris, Beijing, Shanghai and Los Angeles. Yet the vast majority of galleries in our dataset are independently owned, non-star galleries which may behave similarly to their counterparts in smaller or mid-sized markets. For instance, the expectation that galleries in Chicago and Santa Fe would also seek to cluster together and locate near affluent potential consumers is not unreasonable. While it is not feasible to assemble comparable datasets on galleries in other cities, it might be worthwhile to conduct equivalent descriptive analysis using the ZBP data to test for broadly similar geographic trends.

While our results cannot be definitively interpreted as causal, they offer some implications for arts-related public policy. Many cities across the U.S. have established "Arts Districts", offering financial incentives for arts-related activities, including galleries, to locate in blighted areas as a strategy for economic development. Our results suggest that reduced rent or 
other economic incentives may not be effective at luring galleries to such neighborhoods, at least in the absence of a critical mass of other galleries. That is, galleries appear to be less interested in locating near starving artists than in being near one another, and near potential art collectors. 


\section{References:}

Berry, B. 1967. Geography of Market Centers and Retail Distribution. Englewood Cliffs, NJ: Prentice Hall.

Chalfant, Henry, and Tony Silver, directors. 1984. Style Wars.

Chang, Y., A.C. Cutts and R.K. Green. 2005. Did Changing Rents Explain Changing House Prices During the 1990s? Working Paper. George Washington University School of Business: Washington, DC.

Chung, W. and A. Kalnins. 2001. Agglomeration effects and performance: A test of the Texas lodging industry. Strategic Management Journal 22(1): 969-988.

Clark, P.J. and F.C. Evans. 1954. Distance to Nearest Neighbor as a Measure of Spatial Relationships in Populations. Ecology 35(4): 445-453.

Comunian, Roberta, Faggian Alessandra. and Li Qing Chen. 2010. Unrewarded careers in the creative class: The strange case of Bohemian graduates. Papers in Regional Science 89: 389410.

Comunian, Roberta. 2011. Rethinking the creative city: the role of complexity, networks and interactions in the urban creative economy. Urban Studies 48: 1157-79

Crane, D. 1987. The transformation of the avant-garde: The New York art world, 1940-1985. Chicago: University of Chicago Press.

Currid, E., and S. Williams. 2010. The geography of buzz: art, culture and the social milieu in Los Angeles and New York. Journal of Economic Geography 10 (3): 423.

Currid, Elizabeth. 2007. The Warhol economy: how fashion, art, and music drive New York City. Princeton NJ: Princeton University Press.

Dixon, Philip. 2001. Nearest Neighbor Methods. Iowa State University, Department of Statistics working paper.

Dudey. M. 1990. Competition by Choice: The Effect of Consumer Search on Firm Location Decisions. American Economic Review 80: 1092-1105.

Eaton, B.C and R.G. Lipsey. 1979. Comparison Shopping and the Clustering of Homogenous Firms. Journal of Regional Science 19: 421-435.

Fischer, Jeffrey and Joseph Harrington. 1996. Product Variety and Firm Agglomeration. RAND Journal of Economics 27(2): 281-309.

Florida, R. 2002a. Bohemia and economic geography. Journal of Economic Geography 2 (1): 55. 
Florida, R. L. 2002b. The rise of the creative class: and how it's transforming work, leisure, community and everyday life. Basic Civitas Books.

Fujita, M. and Jean-Francois Thisse. 2002. Economics of Agglomeration. Cambridge: Cambridge University Press.

Greene, William. 1993. Econometric Analysis ( $3^{\text {rd }}$ edition). Upper Saddle River, NJ: Prentice Hall.

Gumpert, L. 2006. Forward. In The downtown book: the New York art scene, 1974-1984, ed. Marvin Taylor. Princeton N.J.: Princeton University Press.

Huff, David L.1964. Defining and Estimating a Trading Area. Journal of Marketing, 24(3): 3438.

Herskovic, Marika. 2000. New York school: abstract expressionists: artists choice by artists: a complete documentation of the New York painting and sculpture annuals, 1951-1957. New Jersey: New York School Press.

Julier, Guy. 2005. The culture of design. New York: Sage Publications.

Kennedy, Randy. 2006. Chelsea: The Art and Commerce of One Hot Block. The New York Times.

Kim, Hakhee. 2007. The creative economy and urban art clusters: locational characteristics of art galleries in Seoul. Journal of the Korean Geographical Society 42 (2): 258-279.

Konishi, H. 2005. Concentration of competing retail stores. Journal of Urban Economics 58(3): 488-512.

Kostelanetz, R. 2003. Soho: the rise and fall of an artists' colony. Psychology Press.

McDonald, J.F. and R.A. Moffit. 1980. The use of tobit analysis. Review of Economics and Statistics 62: 318-321.

Meltzer, Rachel and Jenny Schuetz. 2012. Bodegas or Bagel Shops? Neighborhood differences in retail and household services. Economic Development Quarterly 26(1): 73-94.

Molotch, H., and M. Treskon. 2009. Changing Art: SoHo, Chelsea and the Dynamic Geography of Galleries in New York City. International Journal of Urban and Regional Research 33 (2): 517-541.

Mommaas, H. 2004. Cultural Clusters and the Post-industrial City: Towards the Remapping of Urban Cultural Policy, Urban Studies, Vol. 41, No. 3, 507-532. 
National Endowment for the Arts. 2011. Artists and Arts Workers in the United States. NEA Research Note \#105. http://www.nea.gov/research/Notes/105.pdf

O'Connor, J. 2002. Public and Private in the Cultural Industries. In Lifestyle, Desire and Politics: Contemporary Identities, edited by T. Johansson and O. Sernhede: Centre for Cultural Studies, University of Gothenburg.

Perl, J. 2007. New art city: Manhattan at mid-century. Vintage.

Picone, Gabriel A., David B. Ridley and Paul Zandbergen. 2009. Distance Decreases with Differentiation: Strategic Agglomeration by Retailers. International Journal of Industrial Organization 27(3): 463-473.

Rosenthal, Stuart. 2008. Old Homes, Externalities, and Poor Neighborhoods: A Model of Urban Decline and Renewal. Journal of Urban Economics 63(3): 816-840.

Schuetz, Jenny, Jed Kolko and Rachel Meltzer. 2012. Are Poor Neighborhoods "Retail Deserts"? Regional Science and Urban Economics 42(1): 269-285.

Shkuda, Aaron. 2010. From Urban Renewal to Gentrification: Artists, Cultural Capital and the Remaking of the Central City. PhD dissertation, University of Chicago.

Simpson, C. R. 1981. SoHo: The artist in the city. University of Chicago Press.

Stahl, K. 1982. Differentiated Products, Consumer Search and Locational Oligopoly. Journal of Industrial Economics 31: 97-113.

Taylor, Marvin. 2006. The downtown book: the New York art scene, 1974-1984. Princeton N.J.: Princeton University Press.

Thompson, Donald N. 2008. The \$12 million stuffed shark: the curious economics of contemporary art. Macmillan.

Waldfogel, Joel. 2008. The median voter and the median consumer: Local private goods and population composition. Journal of Urban Economics 63: 567-582.

Wolinsky, A. 1983. Retail Trade Concentration Due to Consumers' Imperfect Information. Bell Journal of Economics 14: 275-282.

Wu, Chin-tao. 2003. Privatising Culture: Corporate Art Intervention Since the 1980s. London: Verso Books.

Zukin, S. 1989. Loft living: culture and capital in urban change. NJ: Rutgers University Press. 
Figure 1: Location of Art Galleries in Manhattan (2000)

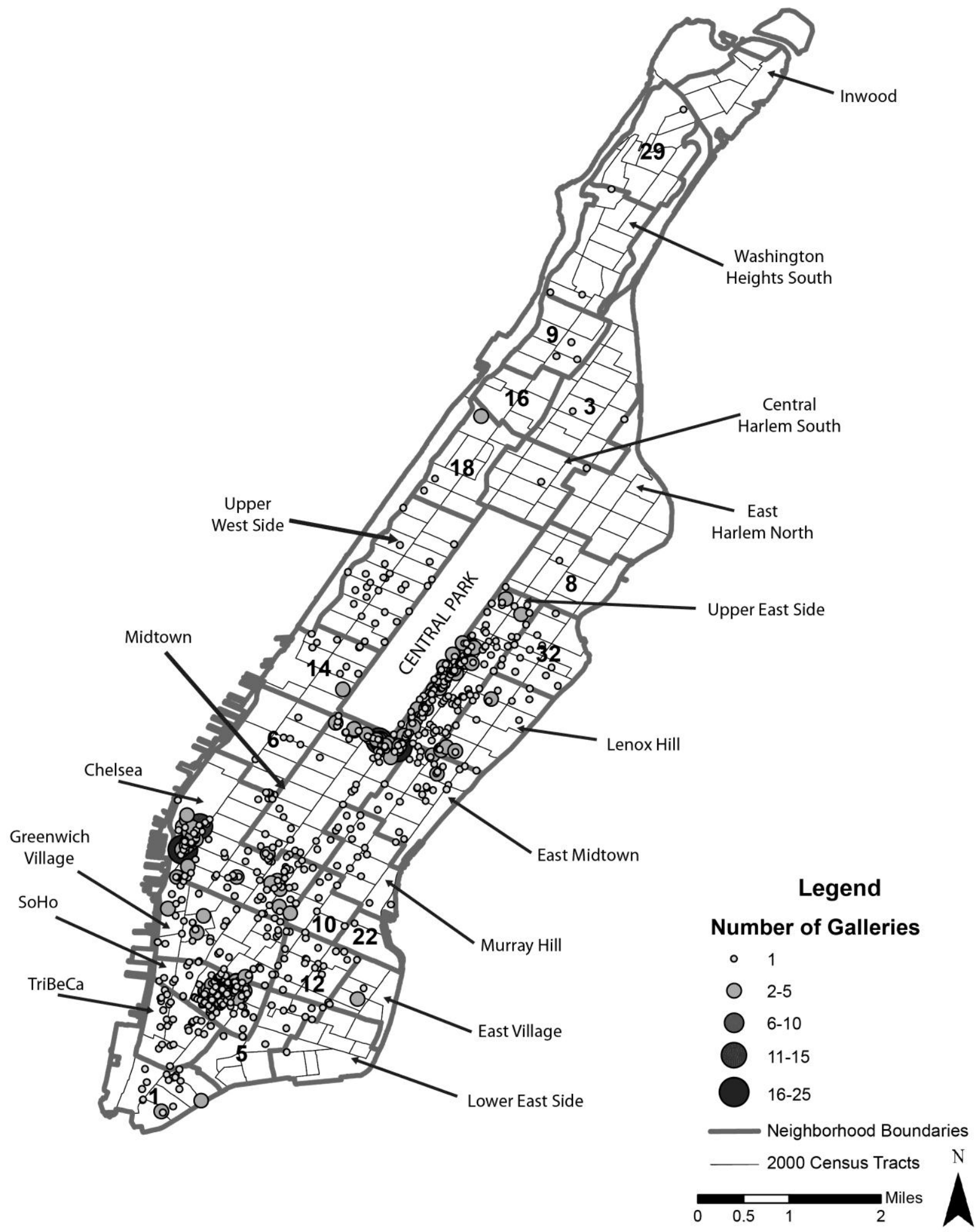

Source: Manhattan Gallery Database 
Figure 2: Location of Soho Art Galleries (1990)
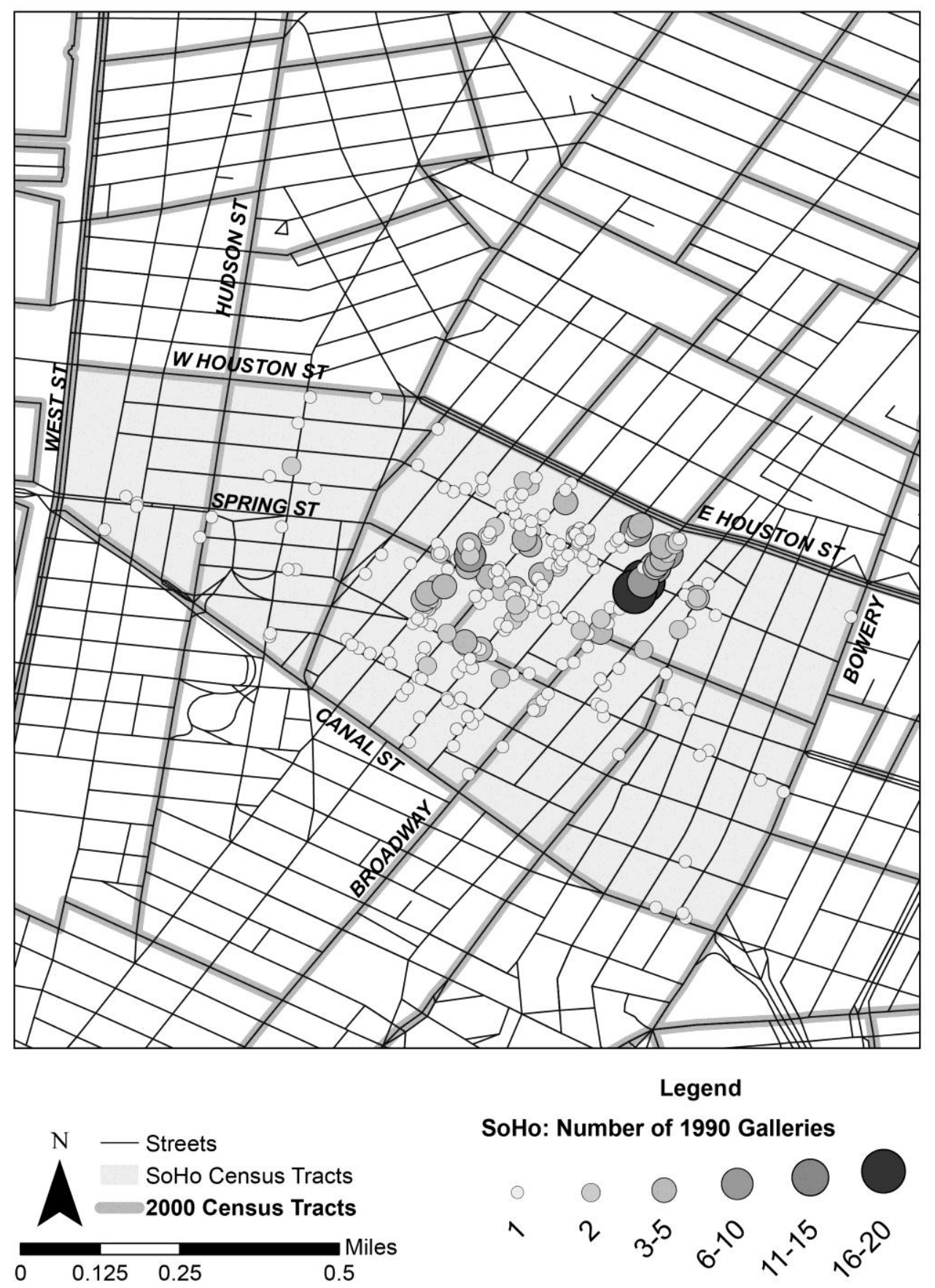

SoHo: Number of 1990 Galleries

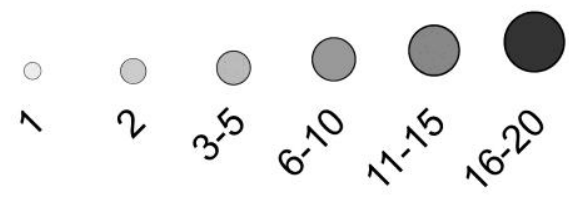

Source: Manhattan Gallery Database 
Figure 3

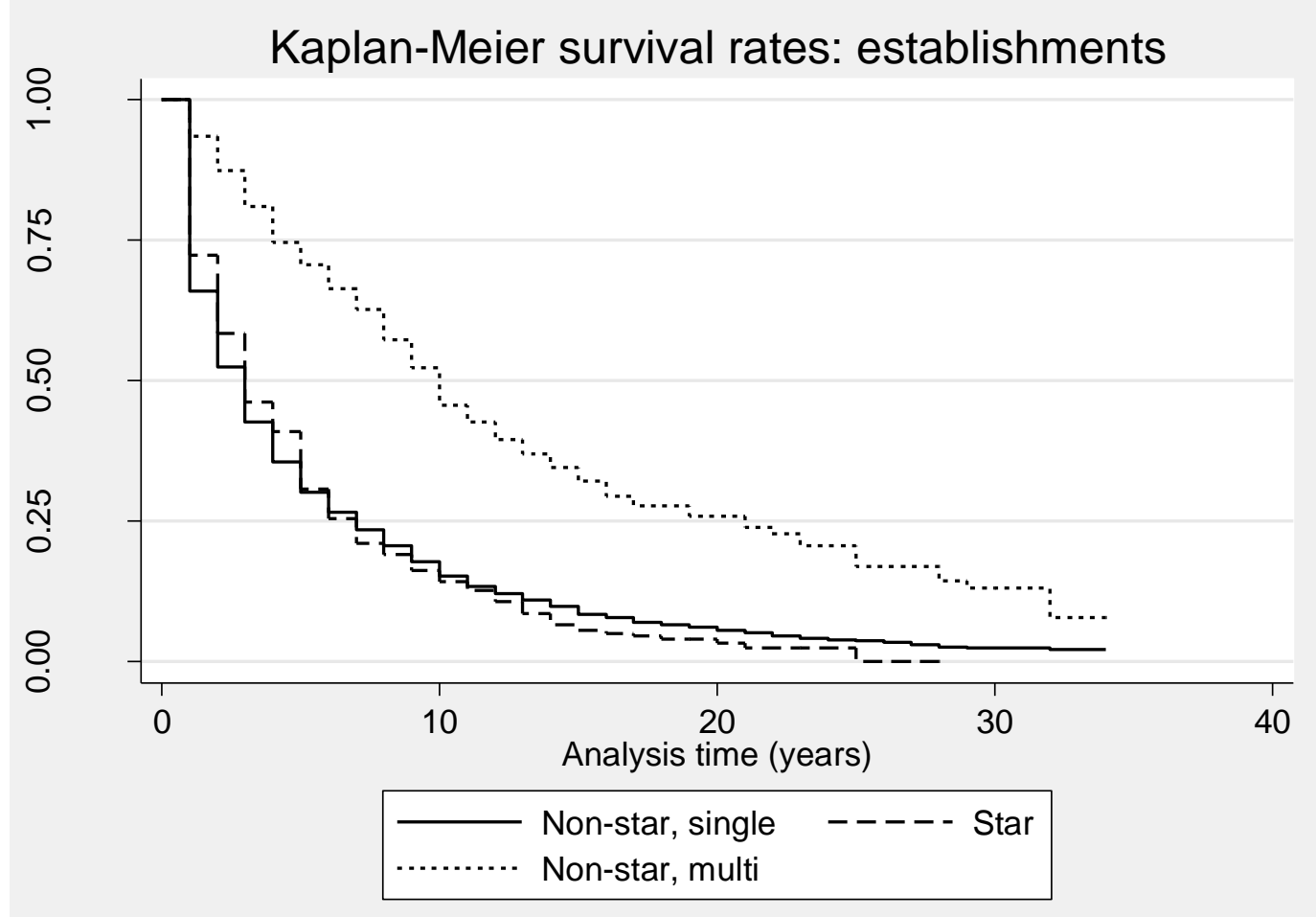

Figure 4

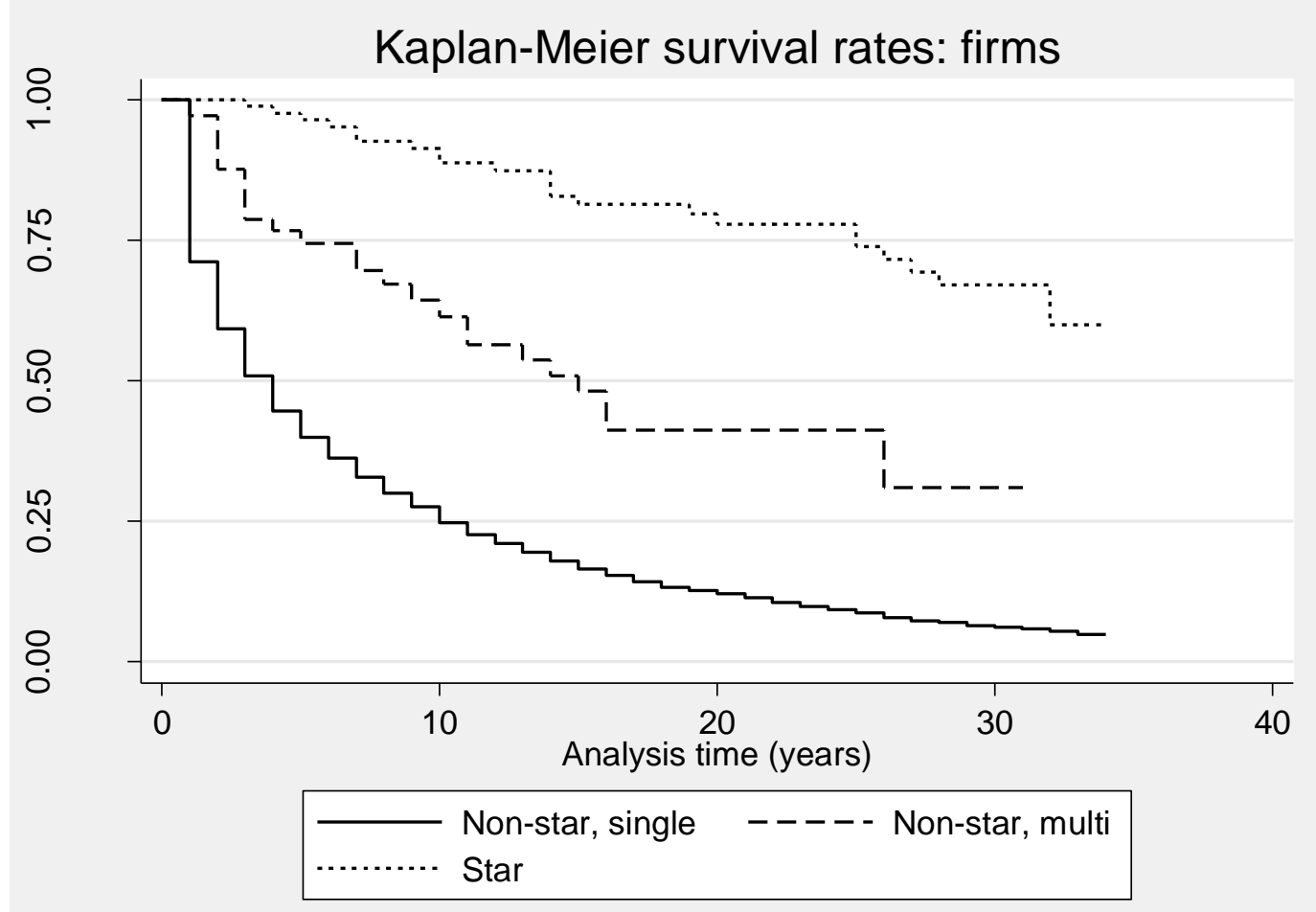


Table 1: Inventory of Manhattan art galleries, by firm type (1970-2003)

\begin{tabular}{|l|c|c|c|c|}
\hline & Firms & \% Firms & Establishments & $\%$ Estabs \\
\hline All firms & 4,526 & & 29,290 & \\
\hline Multi-est & 177 & $3.91 \%$ & 3587 & $12.25 \%$ \\
\hline Stars & 86 & $1.90 \%$ & 1883 & $6.43 \%$ \\
\hline
\end{tabular}

Source: Manhattan Gallery Database.

Table 2: Gallery tenure (years), by firm type

\begin{tabular}{|l|c|c|c|c|c|c|}
\hline & Mean & Median & Min & Max & St dev & $\mathrm{n}$ \\
\hline Firms & & & & & & \\
\hline All firms & 6.45 & 3.00 & 1.00 & 34.00 & 7.40 & 4526 \\
Stars & 20.49 & 20.50 & 3.00 & 34.00 & 10.45 & 86 \\
Non-star, multi-est & 15.28 & 14.00 & 1.00 & 34.00 & 9.66 & 151 \\
\hline Establishments & & & & & & \\
\hline All firms & 4.68 & 3.00 & 1.00 & 34.00 & 5.33 & 6342 \\
Stars & 9.54 & 7.00 & 1.00 & 34.00 & 8.20 & 198 \\
Non-star, multi-est & 6.30 & 5.00 & 1.00 & 33.00 & 5.74 & 460 \\
\hline
\end{tabular}

Source: Manhattan Gallery Database. 
Table 3: Gallery inventory by neighborhood, 1970-2000

\begin{tabular}{|l|cc|cc|cc|cc|}
\hline Neighborhood & 1970 & & 1980 & & 1990 & & 2000 & \\
\hline UES & 255 & $(1)$ & 280 & $(1)$ & 243 & $(1)$ & 215 & $(1)$ \\
Midtown & 112 & $(2)$ & 179 & $(2)$ & 126 & $(3)$ & 128 & $(4)$ \\
Greenwich Vill & 61 & $(3)$ & 65 & $(4)$ & 57 & $(5)$ & 47 & $(5)$ \\
East Midtown & 57 & $(4)$ & 60 & $(5)$ & 60 & $(4)$ & 36 & $(6)$ \\
Lenox Hill/RI & 35 & $(5)$ & 27 & $(6)$ & 27 & $(6)$ & 23 & $(10)$ \\
\hline Murray Hill & 20 & $(6)$ & 11 & $(13)$ & 22 & $(11)$ & 18 & $(12)$ \\
Yorkville & 16 & $(7)$ & 13 & $(10)$ & 16 & $(13)$ & 13 & $(14)$ \\
Chelsea & 13 & $(8)$ & 17 & $(7)$ & 26 & $(8)$ & 155 & $(3)$ \\
East Village & 12 & $(9)$ & 10 & $(14)$ & 27 & $(6)$ & 29 & $(7)$ \\
Gramercy & 11 & $(10)$ & 13 & $(10)$ & 17 & $(12)$ & 22 & $(11)$ \\
\hline UWS & 7 & $(11)$ & 15 & $(8)$ & 23 & $(10)$ & 28 & $(8)$ \\
Soho & 5 & $(12)$ & 72 & $(3)$ & 243 & $(1)$ & 205 & $(2)$ \\
Lincoln Sq & 4 & $(13)$ & 13 & $(10)$ & 14 & $(15)$ & 11 & $(15)$ \\
BPC/Lower MN & 3 & $(14)$ & 8 & $(15)$ & 15 & $(14)$ & 18 & $(12)$ \\
Tribeca & 3 & $(14)$ & 14 & $(9)$ & 26 & $(8)$ & 28 & $(8)$ \\
\hline Cent Harlem N & 2 & $(16)$ & 2 & $(19)$ & 2 & $(18)$ & 1 & $(24)$ \\
Chinatown & 2 & $(16)$ & 4 & $(17)$ & 3 & $(17)$ & 2 & $(21)$ \\
Clinton & 2 & $(16)$ & 4 & $(17)$ & 4 & $(16)$ & 8 & $(17)$ \\
Lower East Side & 2 & $(16)$ & 0 & $(21)$ & 2 & $(18)$ & 9 & $(16)$ \\
Wash Hts N & 2 & $(16)$ & 1 & $(20)$ & 0 & $(22)$ & 1 & $(24)$ \\
\hline Cent Harlem S & 1 & $(21)$ & 0 & $(21)$ & 0 & $(22)$ & 2 & $(21)$ \\
East Harlem S & 1 & $(21)$ & 6 & $(16)$ & 0 & $(22)$ & 2 & $(21)$ \\
Morningside Hts & 1 & $(21)$ & 0 & $(21)$ & 2 & $(18)$ & 4 & $(18)$ \\
East Harlem N & 0 & $(24)$ & 0 & $(21)$ & 0 & $(22)$ & 1 & $(24)$ \\
Hamilton Hts & 0 & $(24)$ & 0 & $(21)$ & 1 & $(21)$ & 3 & $(19)$ \\
\hline Inwood & 0 & $(24)$ & 0 & $(21)$ & 0 & $(22)$ & 0 & $(28)$ \\
Manhattanville & 0 & $(24)$ & 0 & $(21)$ & 0 & $(22)$ & 0 & $(28)$ \\
Parks & 0 & $(24)$ & 0 & $(21)$ & 0 & $(22)$ & 0 & $(28)$ \\
Stuy Town/PCV & 0 & $(24)$ & 0 & $(21)$ & 0 & $(22)$ & 1 & $(24)$ \\
Wash Hts S & 0 & $(24)$ & 0 & $(21)$ & 0 & $(22)$ & 3 & $(19)$ \\
\hline MANHATTAN & 627 & & 814 & & 956 & & 1013 & \\
\hline Sorc: Mat
\end{tabular}

Source: Manhattan Gallery Database. First column in each year indicates number of galleries, number in parentheses is neighborhood ranking. 
Table 4: Variable definitions and sources

\begin{tabular}{lll}
\hline \multicolumn{1}{c}{ Variable } & \multicolumn{1}{c}{ Definition } & \multicolumn{1}{c}{ Source } \\
\hline \hline New galleries & \# newly opened galleries (3-year intervals) & Manhattan Gallery Database \\
Existing gallries & \# galleries in baseline years & Manhattan Gallery Database \\
$\begin{array}{l}\text { Star galleries } \\
\text { Multi-est galleries }\end{array}$ & \# \# multi-est galleries, baseline years & Manhattan Gallery Database \\
Gall density index & Avg distance (miles) from tract center to 5 & Manhattan Gallery Database, \\
& nearest galleries & Census lat-long coordinates \\
& & \\
Pop/acre & Population density, per acre & Census, 1970-2000 \\
Income & Avg HH income & Census, 1970-2000 \\
BA+ & $\%$ pop w/ BA or graduate degree & Census, 1970-2000 \\
White & $\%$ white & Census, 1970-2000 \\
Non-family HH & $\%$ non-family households & Census, 1970-2000 \\
Age 0-17 & $\%$ pop aged 0-17 years & Census, 1970-2000 \\
Age 18-34 & $\%$ pop aged 18-34 years & Census, 1970-2000 \\
Age 35-54 & $\%$ pop aged 35-54 years & Census, 1970-2000 \\
Age 55+ & $\%$ pop aged 55+ years & Census, 1970-2000 \\
& & \\
Museum density & Avg distance from tract center to nearest five & Rough Guide to NYC, museum \\
index & museums & websites \\
Distance CBD & Distance (miles) to Empire State Bldg & Author calc using census lat-long \\
Rent & & coordinates \\
Housing pre-1940 & Avg contract rent (monthly) & Census, 1970-2000 \\
\hline
\end{tabular}


Table 5: Difference in characteristics for new gallery neighborhoods

\begin{tabular}{|l|c|c|cc|}
\hline & NEWGALL $=1$ & NEWGALL $=0$ & Difference & \\
\hline PRIOR GALLERIES & & & & \\
Existing galleries & 6.868 & 0.407 & 6.461 & $* * *$ \\
& $(14.127)$ & $(1.042)$ & & \\
Gall density index & 0.200 & 0.907 & -0.707 & $* * *$ \\
& $(0.261)$ & $(0.858)$ & & \\
\hline ENVIRONMENT & & & & \\
Museum density & 0.733 & 1.337 & -0.604 & $* * *$ \\
& $(0.362)$ & $(0.795)$ & & \\
Distance CBD & 1.857 & 4.071 & -2.214 & $* * *$ \\
& $(1.273)$ & $(2.308)$ & & \\
Rent & 926.907 & 592.190 & 334.717 & $* * *$ \\
& $(365.253)$ & $(340.740)$ & & \\
Housing pre-1940 & 58.552 & 51.764 & 6.788 & $* * *$ \\
& $(23.619)$ & $(29.250)$ & & \\
\hline POPULATION & & & & \\
Pop/acre & 53,829 & 59,236 & $-5,407$ & $* * *$ \\
& $(33,147)$ & $(31,627)$ & & \\
Income & 89,807 & 48,237 & 41,570 & $* * *$ \\
& $(60,549)$ & $(36,438)$ & & \\
BA+ & 47.995 & 24.109 & 23.886 & $* * *$ \\
& $(20.755)$ & $(24.313)$ & & \\
White & 80.758 & 47.913 & 32.845 & $* * *$ \\
& $(21.510)$ & $(33.520)$ & & \\
Non-family HH & 64.798 & 46.366 & 18.432 & $* * *$ \\
& $(13.688)$ & $(17.218)$ & & \\
Age 0-17 & 10.643 & 21.422 & -10.779 & $* * *$ \\
Age 18-34 & $(6.799)$ & $(10.161)$ & & \\
& 34.143 & 29.437 & 4.706 & $* * *$ \\
Age 35-54 & $(11.894)$ & $(10.035)$ & & \\
Age 55+ & 30.417 & 26.006 & 4.412 & $* * *$ \\
& $(6.662)$ & $(6.308)$ & & \\
n= & 24.797 & 23.136 & 1.660 & $* * *$ \\
Res & $(11.402)$ & $(10.190)$ & & \\
\hline
\end{tabular}

Results of difference in means tests for pooled sample across census tract-years. Monetary values reported in constant 2000 dollars. $* * * \mathrm{p}<0.01, * * \mathrm{p}<0.05, * \mathrm{p}<0.1$ 
Table 6: Location of galleries by rent decile

\begin{tabular}{|c|c|c|c|c|c|c|}
\hline & \multicolumn{3}{|c|}{ New gallery tracts } & \multicolumn{3}{|c|}{ Tracts w/ at least one existing gallery } \\
\hline Decile & Rent range & Number & $\%$ & $\%$ & Mean & Median \\
\hline 1 & $100-318$ & 11 & 9.65 & 10.53 & 1.25 & 1 \\
2 & $319-383$ & 14 & 12.28 & 11.40 & 1.38 & 1 \\
3 & $384-458$ & 17 & 14.91 & 15.79 & 2.06 & 1 \\
4 & $459-537$ & 18 & 15.79 & 19.30 & 1.77 & 1 \\
5 & $538-622$ & 32 & 28.07 & 32.46 & 4.03 & 2 \\
6 & $623-738$ & 53 & 46.49 & 43.86 & 5.02 & 2 \\
7 & $739-881$ & 76 & 66.67 & 69.30 & 5.62 & 3 \\
8 & $882-1039$ & 81 & 71.05 & 86.84 & 7.63 & 3 \\
9 & $1040-1268$ & 80 & 70.18 & 82.46 & 9.27 & 4 \\
10 & $1269-2471$ & 73 & 64.60 & 87.61 & 8.32 & 4 \\
\hline Total & 1139 & 455 & 39.95 & 45.92 & 6.51 & 2 \\
\hline
\end{tabular}

Deciles 1-9 have 114 tract-year observations, decile 10 has 113 tract-years. 
Table 7: Difference in gallery neighborhood characteristics, by gallery type

\begin{tabular}{|l|c|c|c|}
\hline & New star & New nonstar & Difference \\
\hline PRIOR GALLERIES & & & \\
Existing galleries & 30.194 & 5.163 & 25.031 *** \\
Gall density index & 0.107 & 0.206 & $-0.099 * *$ \\
\hline ENVIRONMENT & & & \\
Museum density & 0.645 & 0.739 & -0.094 \\
Distance CBD & 1.669 & 1.871 & -0.202 \\
Rent & 1040 & 919 & $121 *$ \\
Housing pre-1940 & 60.166 & 58.434 & 1.732 \\
\hline POPULATION & & & \\
Pop/acre & 42,914 & 54,627 & $-11,713 *$ \\
Income & 123,699 & 87,329 & $36,370 * * *$ \\
BA+ & 49.403 & 47.892 & 1.511 \\
White & 90.193 & 80.068 & $10.125 * * *$ \\
Non-family HH & 62.748 & 64.948 & -2.200 \\
Age 0-17 & 9.231 & 10.746 & -1.515 \\
Age 18-34 & 28.527 & 34.553 & -6.026 *** \\
Age 35-54 & 30.538 & 30.409 & 0.129 \\
Age 55+ & 31.704 & 24.292 & $7.412 * * *$ \\
\hline $\mathrm{n}=$ & 31 & 424 & \\
\hline
\end{tabular}

\begin{tabular}{|c|c|c|c|}
\hline & New multi-est & New single-est & Difference \\
\hline PRIOR GALLERIES & & & \\
\hline Existing galleries & 15.639 & 4.492 & $11.148 * * *$ \\
\hline Gall density index & 0.139 & 0.215 & $-0.077 * * *$ \\
\hline ENVIRONMENT & & & \\
\hline Museum density & 0.65 & 0.76 & $-0.10 * * *$ \\
\hline Distance CBD & 1.73 & 1.89 & -0.17 \\
\hline Rent & 947.92 & 921.21 & 26.70 \\
\hline Housing pre-1940 & 60.57 & 58.00 & 2.57 \\
\hline POPULATION & & & \\
\hline Pop/acre & 50,406 & 54,756 & $-4,351$ \\
\hline Income & 99,079 & 87,294 & $11,785 *$ \\
\hline BA+ & 48.81 & 47.77 & 1.03 \\
\hline White & 87.56 & 78.91 & $8.65 * * *$ \\
\hline Non-family HH & 64.58 & 64.86 & -0.28 \\
\hline Age $0-17$ & 9.61 & 10.92 & $-1.31 *$ \\
\hline Age $18-34$ & 30.40 & 35.16 & $-4.76 * * *$ \\
\hline Age $35-54$ & 31.07 & 30.24 & 0.83 \\
\hline Age $55+$ & 28.92 & 23.68 & $5.24 * * *$ \\
\hline $\mathrm{n}=$ & 97 & 358 & \\
\hline
\end{tabular}


Table 8: What factors affect gallery location decisions?

\begin{tabular}{|c|c|c|c|c|c|}
\hline Dep variable: & New galleries & & & & Ln(galleries) \\
\hline & (1) & (2) & (3) & (4) & (5) \\
\hline Existing galleries & $\begin{array}{c}0.310^{* * * *} \\
(0.051)\end{array}$ & & & $\begin{array}{c}0.237 * * * \\
(0.048)\end{array}$ & $\begin{array}{c}0.641 * * * \\
(0.113)\end{array}$ \\
\hline Gall density index & $\begin{array}{c}-0.533 * * * \\
(0.164)\end{array}$ & & & $\begin{array}{c}-0.414 * * * \\
(0.134)\end{array}$ & $\begin{array}{c}-1.346^{* * * *} \\
(0.450)\end{array}$ \\
\hline Museum density index & & $\begin{array}{c}-0.333^{* * * *} \\
(0.087)\end{array}$ & & $\begin{array}{l}-0.147 \\
(0.092)\end{array}$ & $\begin{array}{l}-0.336^{*} \\
(0.201)\end{array}$ \\
\hline Distance CBD & & $\begin{array}{c}-0.115^{* * *} \\
(0.057)\end{array}$ & & $\begin{array}{l}-0.014 \\
(0.059)\end{array}$ & $\begin{array}{l}-0.089 \\
(0.116)\end{array}$ \\
\hline $\operatorname{Ln}($ Rent $)$ & & $\begin{array}{c}0.278 * * * \\
(0.065)\end{array}$ & & $\begin{array}{l}0.203^{* *} \\
(0.101)\end{array}$ & $\begin{array}{l}0.492^{* *} \\
(0.202)\end{array}$ \\
\hline Housing pre-1940 & & $\begin{array}{c}0.00292^{* * * *} \\
(0.001)\end{array}$ & & $\begin{array}{l}0.001 \\
(0.001)\end{array}$ & $\begin{array}{l}0.0036^{*} \\
(0.002)\end{array}$ \\
\hline Ln(Pop/acre) & & & $\begin{array}{c}0.0691 * * * \\
(0.025)\end{array}$ & $\begin{array}{l}0.031 \\
(0.024)\end{array}$ & $\begin{array}{l}0.104^{*} \\
(0.053)\end{array}$ \\
\hline Ln(Income) & & & $\begin{array}{c}0.481^{* * * *} \\
(0.101)\end{array}$ & $\begin{array}{c}0.298^{* * * *} \\
(0.099)\end{array}$ & $\begin{array}{c}0.845^{* * * *} \\
(0.188)\end{array}$ \\
\hline BA+ & & & $\begin{array}{c}-0.0143 * * * * \\
(0.003)\end{array}$ & $\mid \begin{array}{c}-0.0126^{* * * *} \\
(0.003)\end{array}$ & $\begin{array}{c}-0.0301 * * * * \\
(0.006)\end{array}$ \\
\hline White & & & $\begin{array}{c}0.00294^{*} \\
(0.002)\end{array}$ & $\begin{array}{c}0.00316^{*} \\
(0.002)\end{array}$ & $\begin{array}{c}0.00688^{*} \\
(0.004)\end{array}$ \\
\hline Non-family HH & & & $\begin{array}{c}0.0114^{* * * *} \\
(0.003)\end{array}$ & $\left|\begin{array}{c}0.00921 * * * \\
(0.003)\end{array}\right|$ & $\begin{array}{c}0.0185^{* * * *} \\
(0.007)\end{array}$ \\
\hline Age $0-17$ & & & $\begin{array}{c}-0.0121^{* *} \\
(0.005)\end{array}$ & $\begin{array}{l}0.001 \\
(0.005)\end{array}$ & $\begin{array}{l}-0.005 \\
(0.013)\end{array}$ \\
\hline Age 18-34 & & & $\begin{array}{l}-0.002 \\
(0.003)\end{array}$ & $\begin{array}{l}0.001 \\
(0.003)\end{array}$ & $\begin{array}{l}-0.005 \\
(0.006)\end{array}$ \\
\hline Age $55+$ & & & $\begin{array}{c}-0.00876^{* * * *} \\
(0.003)\end{array}$ & $\begin{array}{l}-0.003 \\
(0.003)\end{array}$ & $\begin{array}{l}-0.008 \\
(0.007)\end{array}$ \\
\hline Year FEs? & Yes & Yes & Yes & Yes & Yes \\
\hline Nhood FEs? & Yes & Yes & Yes & Yes & Yes \\
\hline Observations & 1139 & 1139 & 1139 & 1139 & 1139 \\
\hline Pseudo R-squared & 0.4164 & 0.3779 & 0.395 & 0.4526 & 0.3506 \\
\hline
\end{tabular}

Columns 1-4 show results of probit models on binary indicator of new galleries. Coefficients are marginal effects. Column 5 shows results of a Tobit model, adjusting for left-censored number of galleries at zero. Robust standard errors in parentheses. *** $\mathrm{p}<0.01,{ }^{*} \mathrm{p}<0.05,{ }^{*} \mathrm{p}<0.1$ 
Table 9: Determinants of gallery hazard rates

\begin{tabular}{|l|c|c|c|c|c|c|}
\hline & \multicolumn{3}{|c|}{ Establishment hazard rates } & \multicolumn{3}{|c|}{ Firm hazard rates } \\
VARIABLES & $(1)$ & $(2)$ & $(3)$ & $(4)$ & $(5)$ & $(6)$ \\
\hline Ln(galleries) & $-0.163 * * *$ & $-0.147^{* * *}$ & $-0.151^{* * *}$ & $-0.217^{* * *}$ & $-0.200^{* * * *}$ & $-0.201 * * *$ \\
& $(0.016)$ & $(0.016)$ & $(0.017)$ & $(0.020)$ & $(0.020)$ & $(0.021)$ \\
Gall density index & $1.122^{* * *}$ & $1.146^{* * *}$ & $1.637 * * *$ & $1.213 * * *$ & $1.204 * * *$ & $1.670^{* * *}$ \\
& $(0.248)$ & $(0.249)$ & $(0.280)$ & $(0.280)$ & $(0.282)$ & $(0.326)$ \\
Stars & & $-0.717 * * *$ & $-0.709^{* * *}$ & & $-1.841^{* * *}$ & $-1.830^{* * *}$ \\
& & $(0.074)$ & $(0.074)$ & & $(0.196)$ & $(0.196)$ \\
Multi-est (non-star) & & -0.018 & -0.021 & & $-0.925^{* * *}$ & $-0.913 * * *$ \\
& & $(0.058)$ & $(0.058)$ & & $(0.189)$ & $(0.188)$ \\
\hline Other controls & $\mathrm{N}$ & $\mathrm{N}$ & $\mathrm{Y}$ & $\mathrm{N}$ & $\mathrm{N}$ & $\mathrm{Y}$ \\
\hline Nhood fixed effects & $\mathrm{Y}$ & $\mathrm{Y}$ & $\mathrm{Y}$ & $\mathrm{Y}$ & $\mathrm{Y}$ & $\mathrm{Y}$ \\
\hline Year fixed effects & $\mathrm{Y}$ & $\mathrm{Y}$ & $\mathrm{Y}$ & $\mathrm{Y}$ & $\mathrm{Y}$ & $\mathrm{Y}$ \\
\hline Num subjects & 6,342 & 6,342 & 6,333 & 4,526 & 4,526 & 4,522 \\
\hline Num failures & 5,472 & 5,472 & 5,464 & 3,672 & 3,672 & 3,667 \\
\hline Log-likelihood & $-43,548$ & $-43,508$ & $-43,409$ & $-28,030$ & $-27,943$ & $-27,882$ \\
\hline Observations & 29,290 & 29,290 & 29,249 & 28,511 & 28,511 & 28,470 \\
\hline
\end{tabular}

All estimates are hazard ratios from Cox proportional hazard models. Robust standard errors, clustered by unique establishment, in parentheses. Models 3 and 6 include controls for museum density, distance to CBD, $\ln ($ rent), \% housing pre 1940, $\ln$ (pop/acre), $\ln$ (income), BA+, white, non-family HH, age 0-17, age 18-34 age 55plus. *** $\mathrm{p}<0.01, * * \mathrm{p}<0.05, * \mathrm{p}<0.1$ 
Appendix Table A: Neighborhood definitions

\begin{tabular}{|c|c|c|}
\hline Neighborhood name & PUMA & Census tracts \\
\hline Battery Park City/Lower MN & 3810 & $7,9,13,15.01,15.02,317.01$ \\
\hline Central Harlem South & 3803 & $\begin{array}{l}\text { 186, 190, 197.02, 200, 201.02, 207.02, 209.02, 216, 218, } \\
220,222\end{array}$ \\
\hline Central Harlem North & 3803 & $\begin{array}{l}206,208,212,213.02,214,217.02,221.02,224,226, \\
227.02,228,230,231.02,232,234,235.02,236,243.02\end{array}$ \\
\hline Chelsea & 3807 & $54,58,81,83,87,89,91,93,95,97,99$ \\
\hline Chinatown & 3809 & $8,16,25,27,29$ \\
\hline Clinton & 3807 & $115,117,121,127,129,133,135,139$ \\
\hline East Harlem North & 3804 & $178,180,182,184,188,192,194,196,198,202,204,210$ \\
\hline East Harlem South & 3804 & $\begin{array}{l}156.02,158.02,160.02,162,164,166,168,170,172.01, \\
172.02,174.01,174.02\end{array}$ \\
\hline Hamilton Heights & 3802 & $225,227.01,229,231.01,233,235.01,237$ \\
\hline Gramercy & 3808 & $48,50,52,56,64,68$ \\
\hline Greenwich Village & 3810 & $55.01,55.02,57,59,61,63,65,67,69,71,73,75,77,79$ \\
\hline East Village & 3809 & $\begin{array}{l}20,22.02,24,26.01,26.02,28,30.02,32,34,36.02,38,40, \\
42\end{array}$ \\
\hline Lenox Hill - Roosevelt Island & 3805 & $106.02,110,116,118,124,126,132,134,238$ \\
\hline Lincoln Square (UWS) & 3806 & $145,147,149,151,153,155,157,159$ \\
\hline Lower East Side & 3809 & $\begin{array}{l}2.01,2.02,6,10.01,10.02,12,14.01,14.02,18,22.01, \\
30.01,36.01\end{array}$ \\
\hline Manhattanville & 3802 & $213.01,217.01,219,221.01,223.01,223.02$ \\
\hline Inwood & 3801 & $289,291,293,295,301,303,307,309$ \\
\hline Morningside Heights & 3802 & $\begin{array}{l}\text { 193, 195, 197.01, 199, 201.01, 203, 205, 207.01, 209.01, } \\
211\end{array}$ \\
\hline Murray Hill - Kips Bay & 3808 & $44.02,62,66,70,72,78,80,82$ \\
\hline Soho & 3810 & $41,43,45,47,49,51,53$ \\
\hline Tribeca & 3810 & $21,31,33,39$ \\
\hline Stuyvesant Town/Peter Cooper Village & 3808 & $44.01,60$ \\
\hline Yorkville (UES) & 3805 & $136,138,144.01,144.02,146.01,146.02,152,154,156.01$ \\
\hline $\begin{array}{l}\text { Parks (Battery, Central, Ellis Island/Liberty } \\
\text { Island, Governors, High Bridge, Hudson } \\
\text { River, Inwood Hill, Randalls/Wards Island, } \\
\text { Riverside) }\end{array}$ & $\begin{array}{l}3801,3804 \\
3806,3810\end{array}$ & $1,5,143,240,297,311,313,315,317.02,319$ \\
\hline Midtown - Midtown South & 3807 & $\begin{array}{l}\text { 74, 76, 84, 94, 96, 101, 102, 103, 104, 109, 111, 112.01, } \\
112.02,113,119,125,131,137\end{array}$ \\
\hline East Midtown/Turtle Bay & 3808 & $86,88,90,92,98,100,106.01,108,112.03$ \\
\hline Upper West Side & 3806 & $\begin{array}{l}161,163,165,167,169,171,173,175,177,179,181,183, \\
185,187,189,191\end{array}$ \\
\hline Upper East Side & 3805 & $\begin{array}{l}\text { 114.01, 114.02, 120, 122, 128, 130,140, 142, 148.01, } \\
148.02,150.01,150.02,158.01,160.01\end{array}$ \\
\hline Washington Heights North & 3801 & $267,269,271,273,275,277,279,281,283,285,287$ \\
\hline Washington Heights South & 3801 & $\begin{array}{l}239,241,243.01,245,247,249,251,253,255,261,263, \\
265\end{array}$ \\
\hline
\end{tabular}


Appendix Table B: Variable summary statistics

\begin{tabular}{lccccc}
\hline \multicolumn{1}{c}{ Variable } & Obs & Mean & Std. Dev. & Min & Max \\
\hline New galleries & 1139 & 1.64 & 5.13 & 0 & 90 \\
Existing gallries & 1139 & 2.99 & 9.50 & 0 & 129 \\
Star galleries & 1139 & 0.18 & 1.15 & 0 & 18 \\
Multi-est galleries & 1139 & 0.34 & 1.47 & 0 & 20 \\
Gallery density index & 1139 & 0.624 & 0.768 & 0.015 & 4.744 \\
& & & & & \\
Pop/acre & 1139 & 57,076 & 32,337 & 44 & 154,445 \\
Income & 1139 & 64,843 & 51,714 & 6,248 & 502,520 \\
BA+ & 1139 & 33.65 & 25.76 & 0 & 86.38 \\
White & 1139 & 61.03 & 33.44 & 0 & 100.00 \\
Non-family HH & 1139 & 53.73 & 18.28 & 0 & 100.00 \\
Age 0-17 & 1139 & 17.12 & 10.41 & 0 & 63.44 \\
Age 18-34 & 1139 & 31.32 & 11.05 & 0 & 86.91 \\
Age 35-54 & 1139 & 27.77 & 6.80 & 0 & 97.78 \\
Age 55+ & 1139 & 23.80 & 10.72 & 0 & 100.00 \\
& & & & & \\
Museum density & 1139 & 1.096 & 0.721 & 0.182 & 4.418 \\
Distance CBD & 1139 & 3.19 & 2.24 & 0 & 9.71 \\
Rent & 1139 & 725.90 & 387.05 & 100 & 2470.71 \\
Housing pre-1940 & 1139 & 54.48 & 27.33 & 0 & 100.00 \\
\hline \hline
\end{tabular}

